University of Louisville

ThinkIR: The University of Louisville's Institutional Repository

$5-2018$

\title{
Therapeutic potential of a plant-made cholera toxin $b$ subunit variant for the treatment of ulcerative colitis.
}

Joshua Mark Royal

University of Louisville

Follow this and additional works at: https://ir.library.louisville.edu/etd

Part of the Medical Pharmacology Commons

\section{Recommended Citation}

Royal, Joshua Mark, "Therapeutic potential of a plant-made cholera toxin b subunit variant for the treatment of ulcerative colitis." (2018). Electronic Theses and Dissertations. Paper 2936.

https://doi.org/10.18297/etd/2936

This Master's Thesis is brought to you for free and open access by ThinkIR: The University of Louisville's Institutional Repository. It has been accepted for inclusion in Electronic Theses and Dissertations by an authorized administrator of ThinkIR: The University of Louisville's Institutional Repository. This title appears here courtesy of the author, who has retained all other copyrights. For more information, please contact thinkir@louisville.edu. 
THERAPEUTIC POTENTIAL OF A PLANT-MADE CHOLERA TOXIN B SUBUNIT

VARIANT FOR THE TREATMENT OF ULCERATIVE COLITIS

\author{
By \\ Joshua Mark Royal \\ B.S., Western Kentucky University, 2013

\begin{abstract}
A Thesis
Submitted to the Faculty of the

School of Medicine of the University of Louisville

In Partial Fulfillment of the Requirements for the Degree of
\end{abstract}

Master of Science in Pharmacology and Toxicology

Department of Pharmacology and Toxicology

University of Louisville

Louisville, KY

May 2018 
Copyright 2018 by Joshua Mark Royal

All rights reserved 

THERAPEUTIC POTENTIAL OF A PLANT-MADE CHOLERA TOXIN B SUBUNIT VARIANT FOR THE TREATMENT OF ULCERATIVE COLITIS

\author{
By \\ Joshua M. Royal \\ B.S. Western Kentucky University, 2013
}

Thesis Approved on

April 18, 2018

By the following Thesis Committee:

Nobuyuki Matoba, Ph.D.

Brian Ceresa, Ph.D.

Leah Siskind, Ph.D.

Kavitha Yaddanapudi, Ph.D.

Chi Li, Ph.D. 


\title{
DEDICATION
}

This thesis is dedicated to my wife

\author{
Ellie F. Royal \\ And my Parents
}

Mr. Timothy Royal and Mrs. Sheilia Royal,

Who have supported me at home throughout this process

And

Nobuyuki Matoba, Ph.D.

Whose mentorship exemplifies selflessness, fairness, and wisdom.

七転び八起き 


\section{ACKNOWLEDGEMENTS}

I am exceptionally appreciative to my Mentor, Dr. Nobuyuki Matoba, for guiding me through my adolescence as a scientist and always pushing me to achieve greatness. Also, I would like to thank my wife, Ellie Royal, who from the beginning supported me and encouraged me throughout this process and to press on when times were tough, she deserves more thanks then I could possibly express here. Lastly, I am extremely grateful of the love and encouragement I have receive from my parents and brothers throughout my time here at the University of Louisville. 


\begin{abstract}
THERAPEUTIC POTENTIAL OF A PLANT-MADE CHOLERA TOXIN B SUBUNIT VARIANT FOR THE TREATMENT OF ULCERATIVE COLITIS

Joshua Mark Royal

April 4, 2018

Cholera toxin B subunit $(\mathrm{CTB})$ is a mucosal immunomodulatory protein that induces robust mucosal and systemic antibody responses. This well-known biological activity has been exploited in cholera prevention (as a component of Dukoral ${ }^{\circledR}$ vaccine) and vaccine development for decades. On the other hand, several studies have investigated CTB's immunotherapeutic potential in the treatment of inflammatory diseases such as Crohn's disease and asthma. Furthermore, we recently found that a plant-made variant of CTB (CTBp) could induce colon epithelial wound healing in mouse colitis models. In this thesis, it is revealed that the wound healing effects are unique to the plant-made variant, as it has an ER retention signal KDEL sequence that provides the protein with new functions. This was determined by investigating how the C-terminal KDEL sequence contributes to the protein's wound healing activity in vivo, in vitro, and ex vivo. In a mouse model of dextran sodium sulfate (DSS)-induced colitis, CTBp, but not CTB, mitigated colitis as characterized by lower disease activity index and inflammation scores, colon shrinkage protection, blunted escalation of blood leukocyte levels, and observable histological epithelial restitution. In vitro, a Caco2 cell wound
\end{abstract}


healing model revealed CTBp's epithelial healing activity, intracellular retention, and unique signaling pathways that were reliant on the protein's KDEL sequence. It was determined that, upon internalization of CTBp, the KDEL sequence enables ER colocalization and retention of the protein, leading to the activation of the inositolrequiring enzyme 1 (IRE1)/X-box binding protein 1 (XBP1) arm of unfolded protein response and subsequent TGF $\beta$ signaling. Lastly, using a ulcerative colitis (UC) patient colon explants, CTBp's therapeutic potential was evaluated, which demonstrated efficacy as manifested by the induction of $T G F B$ gene expression, upregulation of wound healing pathways and presence of viable crypts in the mucosa. In summary, CTBp exhibits unique colon mucosal would healing effects that are mediated by its colocalization to the ER and subsequent activation of IRE1/XBP1 signaling in colon epithelial cells. Furthermore, the results presented herein provide implications for the unique therapeutic potential of CTBp that may address a significant unmet need in UC treatment. 


\section{TABLE OF CONTENTS}

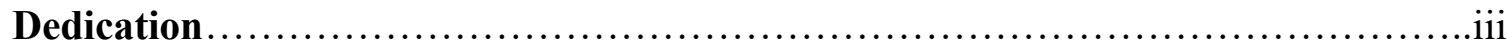

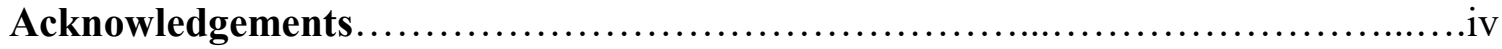

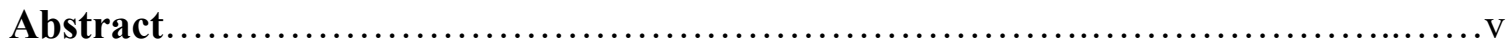

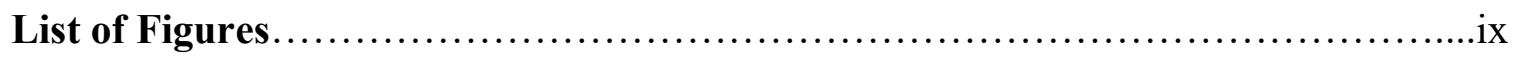

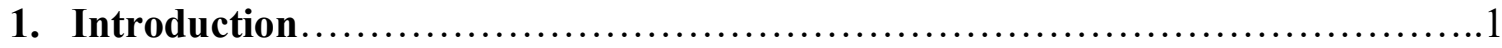

1.1. Cholera Toxin Structure and Mechanism in Gut Epithelial Cells ..................3

1.2. Mode of Action: CTB Directly Modulates Immune and Epithelial Cells............5

1.2.1. CTB Directly Impacts Immune Cells ..............................6

1.2.2. A Plant-Made CTB variant (CTBp) Directly Modulates Epithelial

Cells............................................................10

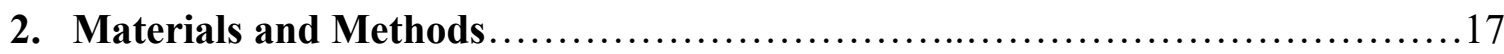

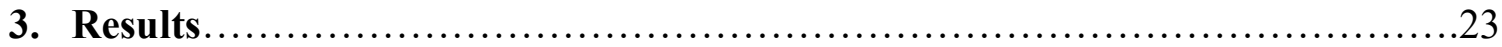

3.1. CTBp uniquely mitigates DSS-induced acute colonic injury and

inflammation .....................................................20

3.2. CTBp uniquely enhances wound closure and TGF $\beta$ levels in human colonic

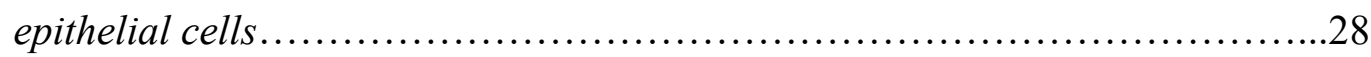

3.3. The C-terminal KDEL sequence is essential for the colon epithelial wound

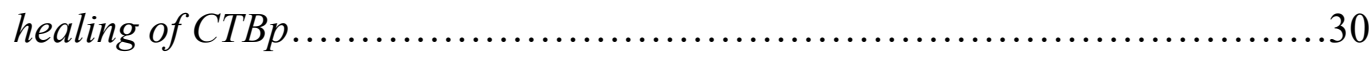

3.4. CTBp induces an unfolded protein response and IRE1-XBP1 signaling in Caco2

cells........................................................... 34 
3.5. CTBp induces a wound healing response in a human ulcerative colitis patient

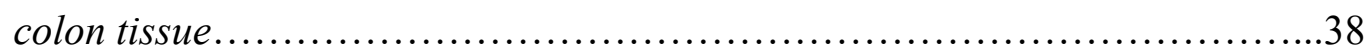

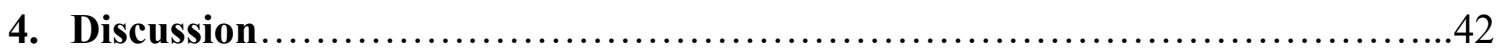

5. Conclusions-Challenges for the Use of CTBp as an Immunomodulatory

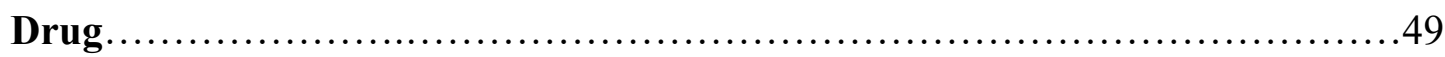

References.............................................................. 53

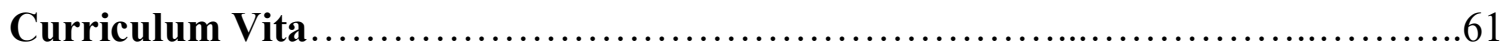




\section{LIST OF FIGURES}

\section{FIGURE}

1. Summary of mechanisms involved in cholera toxin homopentameric b-subunit (CTB)'s inflammatory disease interventio.

2. Effects of orally administered rCTB or CTBp in an acute DSS-colits model................................................................ 25

3. CTBp and $\mathrm{rCTB}$ effects on mouse colon histological alterations induce by DSScolitis. .27

4. CTBp's in vivo activity in DSS-induced colitis is not gender specific.

5. CTBp, but not $\mathrm{rCTB}$, enhances wound healing and TGF $\beta$ levels in a human colon epithelial cell wound healing model.

6. Analysis of CTB variants on human colon epithelial cells. 33

7. Immunofluorescence analysis of CTBp or $\mathrm{rCTB}$ intracellular localization within the

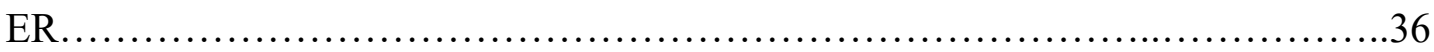

8. The affects of the UPR on CTBp's wound healing activity........................

9. Human UC patient colectomy tissue RT-qPCR analysis........................40

10. Human UC patient colectomy tissue H\&E stain.............................. 43 


\section{INTRODUCTION}

Vibrio cholerae is a gram-negative bacterium that can colonize the gastrointestinal tract and cause life-threatening watery diarrhea. The principal virulence factor of $V$. cholerae is cholera toxin (CT), which consists of a catalytic A-subunit and a non-toxic homopentameric B-subunit (CTB) [1-3]. CTB binds cells through GM1 ganglioside receptors, which then mediates toxin entry into the cell. It has been previously shown that CTB can induce strong biological activities that can enhance or suppress immune effects under normal and various immunopathological conditions without the toxicity associated with the CTA subunit [4]. Consequently, CTB has been widely studied as a mucosal immunomodulatory agent.

In its most well-known immunostimulatory effects, CTB is used in the vaccine Dukoral ${ }^{\circledR}$. Dukoral ${ }^{\circledR}$ is a WHO pre-qualified oral cholera vaccine which contains heatkilled whole cell $V$. cholerae and recombinant CTB (rCTB; Table 1). Dukoral ${ }^{\circledR}$ stimulates the production of both antibacterial and antitoxin antibodies, including secretory immunoglobulin A (S-IgA) produced locally in the intestines [5]. CTB itself can induce potent mucosal and systemic antibody response upon mucosal administration in humans [6-8], which is largely due to the broad distribution of GM1 ganglioside on various cell types such as epithelial cells, macrophages, dendritic cells (DCs), B cells, T cells, and

neurons [9-12]. Furthermore, the presence of GM1 ganglioside on the luminal surface of 
intestinal epithelial cells and antigen presenting cells (APCs) in the gut seems to be essential for CTB's strong mucosal immunostimulatory effects associated with MHC class II expression and local antigen enrichment [13]. Due to CTB's strong mucosal immunomodulatory effects and the use of CTB in the vaccine Dukoral, the production of the protein in various recombinant production platforms has been widespread. These include eukaryotes yeast cells to multicellular organisms such as plants and silkworms, as well as, prokaryotic cells such as genetically modified V. cholerae, E. coli, Bacillus and Lactobacillus (reviewed in [4]). In cell culture systems recombinant (r)CTB is produced in fermenters and bioreactors [4]. Alternatively, in plant expression systems, $\mathrm{rCTB}$ is expressed in whole plants grown in controlled growth rooms or greenhouses. Previously, our lab has produced recombinant CTB in tobacco plants (Nicotiana benthamiana) using a plant virus vector overexpression system (CTBp; plant-made CTB; Table 1), with the aim to economically mass-produce the vaccine antigen to facilitate global cholera vaccination [14-16]. CTBp was generated as a result of this endeavor; we genetically modified CTB to add an ER retention signal to the C-terminus, which was critical to mitigate ER stress/tissue necrosis upon overexpression and achieve high-level accumulation in leaf tissue $[14,15]$. Our analyses demonstrated that CTBp is virtually identical to original CTB in regard to GM1-ganglioside binding affinity, molecular stability and vaccine efficacy to induce anti-toxin $\operatorname{IgG}$ and $\operatorname{Ig} \mathrm{A}$ antibodies upon oral immunization in mice [14]. Subsequently, we established a facile and scalable CTBp production process, which allows us to obtain $400 \mathrm{mg}$ of the purified protein from $1 \mathrm{~kg}$ of leaf biomass (corresponding to 400 doses of Dukoral vaccine), with quality that can meet pharmaceutical standards [17]. 
In addition to CTB's immunostimulatory effects, CTB stimulates specific immunosuppressive effects against autoimmune disorders, excess inflammation, and allergic reactions [4, 18-22]. We have recently shown that oral administration of CTBp mitigates colitis in chemically-induced acute and chronic colitis mouse models [23]. Although the underlying mechanisms are not well understood, recent studies have shed some light on these immunosuppressive effects induced by CTB. In this chapter, I summarize possible mechanisms behind CTB's anti-inflammatory activity and discuss how the protein could impact mucosal inflammatory disease treatment.

\subsection{CHOLERA TOXIN STRUCTURE AND MECHANISM IN GUT EPITHELIAL CELLS}

To reveal the mechanism of CTB-induced biological activity, we must first understand the molecule. CT is classified as an AB5 toxin family, which includes the toxins of Shigella dysenteriae and enterohaemorrhagic Escherichia coli. The toxins are usually composed of one A subunit and five B subunits (CTA and CTB, respectively, for CT). CTA consists of an enzymatically active 11-kDa N-terminal chain (CTA1) and a Cterminal chain (CTA2) that connects CTA to the central pore of CTB. CTB has the capacity to translocate the CTA across the plasma membrane, mediated by the binding of GM1 ganglioside, and then escort CTA from the plasma membrane into the endoplasmic reticulum (ER) $[24,25]$. The following summarizes CT's retrograde trafficking mechanism.

The five B-subunits form a central cylindrical pore lined by five amphipathic $\alpha$ helices that help form a highly stable homopentamer. The pentamer contains five GM1 
binding sites that lie on the outer edge of each $\mathrm{B}$ subunit $[1,26]$. Due to an avidity effect from the pentavalent binding capacity, CTB has a very strong affinity ( $\mathrm{K}_{\mathrm{D}}$ reported to be $5 \mathrm{pM}$ to $1 \mathrm{nM}$ ) to GM1, which is mainly localized in lipid rafts on the plasma membranes of many cell types [9-12]. Once CT is bound to GM1 (up to five gangliosides at once), it is endocytosed by clathrin-dependent and independent mechanisms and trafficked via retrograde transport from the Golgi to the ER [25]. It is also known that CT can undergo transcytosis across epithelial cells from the apical to the basolateral surface. However, regardless of how the toxin enters the cell, CT travels to the trans-Golgi network via early endosomal vesicles, independent of the late endosome pathway. The C-terminus of CTA2 possesses a KDEL ER-retention signal for retrieval of CT from the cis-Golgi apparatus to the ER. Interestingly, the KDEL sequence is not vital for retrograde transport of CT to the ER. Mutations that alter the KDEL sequence on CT inhibit KDEL-dependent ER retrieval and decreased (albeit not completely) CT's toxification [27]. Thus, it is thought that CT's KDEL sequence — although not absolutely essential—improves the ER's retrieval of the dissociated CT from the Golgi apparatus and prolongs the time of retention within the ER [24, 27, 28]. Once in the ER, the CTA1-chain is dissociated from CTA2/CTB complex by protein disulfide isomerase (PDI). Subsequently, CTA1 enters the cytosol via the ER-associated degradation pathway and escapes proteasomal degradation [1,24]. On the other hand, the fate (and remaining function, if any) of CTA2/CTB after releasing CTA1 in the ER is not well documented. Meanwhile, CTA1 reaches the inner surface of the plasma membrane and catalyzes the ADP ribosylation of Gas, thereby continuously activating adenylate cyclase to produce cAMP. Increased intracellular cAMP impairs sodium uptake and increases chloride outflow, leading to water secretion and diarrhea [24, 29]. 


\section{CELLS}

Although the virulence mechanism and intracellular trafficking of CT has been well studied, the anti-inflammatory mechanisms of CTB are much less studied and understood. After a comprehensive literature review, it seems that there are at least two separate modes of action induced by CTB to modulate inflammatory responses: one that is based on immune cell regulation, and another that is epithelial cell-mediated (Figure $1)$.

In 1994, the immune suppressive effects of CTB were first reported by Sun et al. [30]. This report demonstrated that oral administration of mice with CTB conjugated with antigens (sheep red blood cells, horse red blood cells, and human $\gamma$-globulin) enhanced oral tolerance to the antigens, presumably through efficient presentation of antigens to immune cells in the gut-associated lymphoid tissue and the generation of regulatory cells. In a Commentary to this article, Weiner suggested that CTB could have enhanced tolerance by serving as a "selective mucosal adjuvant" and that this unique activity could be exploited to treat autoimmunity [31]. Subsequently, this seminal finding led to a new field of studies in which CTB-antigen conjugates were applied to induce tolerogenic reactions to the conjugated antigens in various immunopathological conditions (i.e., encephalomyelitis, autoimmune diabetes, autoimmune arthritis, uveitis) and IgEmediated allergen hypersensitivity [18, 20-22, 32-42]. Through these studies, it became apparent there are two unique and distinct mechanisms of CTB responsible for the suppression of immunopathological reactions in allergy and autoimmune diseases: (1) to 
increase antigen uptake and presentation by different APCs through binding to their cellsurface GM1 ganglioside receptors and (2) to induce anti-inflammatory and immunoregulatory activities by directly or indirectly acting on specific immune cells. The latter mechanism points to the possibility that CTB by itself may act as an immunotherapeutic agent; however, only a handful of groups have actually proven that CTB alone - without co-administration or conjugation of antigens - can induce an antiinflammatory response. Moreover, studies conducted with non-recombinant CTB (nrCTB, prepared by chemically dissociating CTA from CTB; Table 1) can have significantly skewed experimental results due to trace amounts of CT and CTA remaining in nrCTB samples preparations $[4,43,44]$. For example, we have previously shown that picomolar concentrations $(<10 \mathrm{ng} / \mathrm{mL})$ of CT significantly inhibited lipopolysaccharide (LPS)-induced TNF $\alpha$ production in RAW264.7 cells, while recombinant (r)CTB failed to induce such an effect at a concentration as high as $10 \mu \mathrm{g} / \mathrm{mL}$ [4]. Thus, the use of rCTB is required to evaluate the effects unique to CTB.

\subsubsection{CTB DIRECTLY IMPACTS IMMUNE CELLS}

With regards to CTB's immune cell regulation, Kim et al. demonstrated in murine spleen B cells that $\mathrm{rCTB}$ dose-dependently increased IgA secretion and inhibited B cell growth [45]. In the presence of IL-2, rCTB significantly increased IgA isotype switching in LPSactivated B cells. These effects were reversed by the addition of an anti-TGF $\beta$ or soluble TGF $\beta 1$ receptor, which markedly inhibited rCTB-stimulated IgA response. Further analysis in the same report revealed that $\mathrm{rCTB}$ stimulated IgA2 B cells, upregulated TGF $\beta 1$ mRNA expression, and increased bioactive TGF $\beta 1$ levels, which is known to 
induce IgA isotype switching [45]. Thus, rCTB stimulated a TGF $\beta$-mediated IgA response that was dependent on IL-2 as a cofactor. These findings have contributed to our understandings of how CTB stimulates B cell IgA production, and potentially oral tolerance as well (see below).

It is known that IgA antibodies help maintain mucosal homeostasis and play a role in immune protection $[46,47]$. Thus, it seems possible that rCTB administration could provide therapeutic effects in mucosal autoimmune disorders via IgA induction. For example, in an experimental mouse model of asthma, nrCTB suppressed the ability of DCs to prime for Th2 responses to inhaled allergen via an IgA-dependent manner [48]. In this study, co-administration of ovalbumin (OVA) and $\mathrm{nrCTB}$ suppressed classical features of asthma, including airway eosinophilia, Th2 cytokine synthesis, and bronchial hyperactivity in mice that were pre-sensitized with OVA-stimulated DCs in the lung. Furthermore, nrCTB treatment enhanced DCs' potential to induce Treg cells in vitro; however, these Treg cells did not provide protection when transferred into the airways of naïve mice that received OVA challenge. In contrast, the transfer of B cells from OVA+CTB-DCs-immunized mice to OVA-sensitized naïve mice significantly reduced eosinophilia and lymphocytosis. It was also found that $\operatorname{nrCTB}$ caused a TGF $\beta$-dependent increase in antigen-specific IgA in the airway luminal secretion, and this was attributed to nrCTB's efficacy against the experimental asthma as the therapeutic effects were abrogated in mice lacking luminal IgA transporter (polymeric Ig receptor), which is necessary for the transport of dimeric IgA across the epithelium into the luminal mucosa [49]. 
Meanwhile, IgA may not be the sole factor contributing to CTB's ability to mitigate inflammatory diseases in the mucosa. For example, in the 2,4,6-trinitrobenzene sulfonic acid (TNBS)-induced mouse model of Crohn's disease, daily oral administration over a four-day period of $100 \mu \mathrm{g}$ rCTB after the onset of TNBS-colitis immediately resolved weight loss and reduced inflammation [43]. In this case, the timing of mucosal restitution in regard to $\mathrm{rCTB}$ administration did not likely result in IgA production. In a similar TNBS-colitis study, rCTB administration reduced IL-12 and IFN $\gamma$ secretion, inhibited STAT-4 and STAT-1 activation, and downregulated T-bet expression, indicating that $\mathrm{rCTB}$ inhibited mucosal Th1 cell signaling [50]. Moreover, these results were confirmed in a small multicenter, open-label, and nonrandomized clinical trial in which 15 patients with active $\mathrm{CD}$ received three oral doses of $5 \mathrm{mg}$ rCTB per-week over 2 weeks (six doses total) and were examined 2, 4, 6, and 10 weeks after the start of the study. Of the 12 patients who finished the study per protocol, seven responded to treatment and five were in remission by week six and maintained remission through week 10 as defined by a CD activity index score $\leq 150$ [51]. Of note, side effects seen in $33 \%$ of patients administered with CTB were mild (arthralgia, headache, and pruritus), and no safety concerns were raised throughout the trial [51].

Interestingly, rCTB did not reduce disease severity in an oxazolone-induced colitis model performed by the same group [43]. Oxazolone-induced colitis is mediated by IL-4 driven Th2 cells rather than IL-12/IFN $\gamma$-driven Th1 cells [43]. Thus, it appears that $\mathrm{rCTB}$ administration had a specific effect on specific $\mathrm{T}$ cell functions involved in TNBS-colitis [43]. Although the detailed mechanism by which rCTB inhibited Th1 cell was not elucidated, it is possible that the binding of CTB to GM1 ganglioside on immune 
cells resulted in a signaling cascade of events that led to Th1 inhibition, because nonGM1 binding CTB mutants do not modulate lymphocyte function [52]. In agreement with these findings, rCTB decreased monocyte-derived DC maturation and IL-12 production upon LPS stimulation in vitro [53]. Moreover, rCTB-pretreated, LPSstimulated DCs induced low proliferating T cells that had enhanced production of IL-10 and reduced production of IFN $\gamma$. Rouquete-Jazdanian et al. additionally showed that the binding of rCTB to GM1 ganglioside directly prevented the activation and proliferation of $\mathrm{CD}^{+} \mathrm{T}$ cells [54]. This effect was induced by rCTB-mediated sphingomyelinase activation that subsequently increased the production of ceramides, which are known cell cycle arrest inducers [55]. rCTB also inhibited protein kinase $\mathrm{C} \alpha$, a pro-growth cellular regulator, which was linked to $\mathrm{rCTB}$-induced lipid raft modifications and ceramidemediated inactivation $[56,57]$.

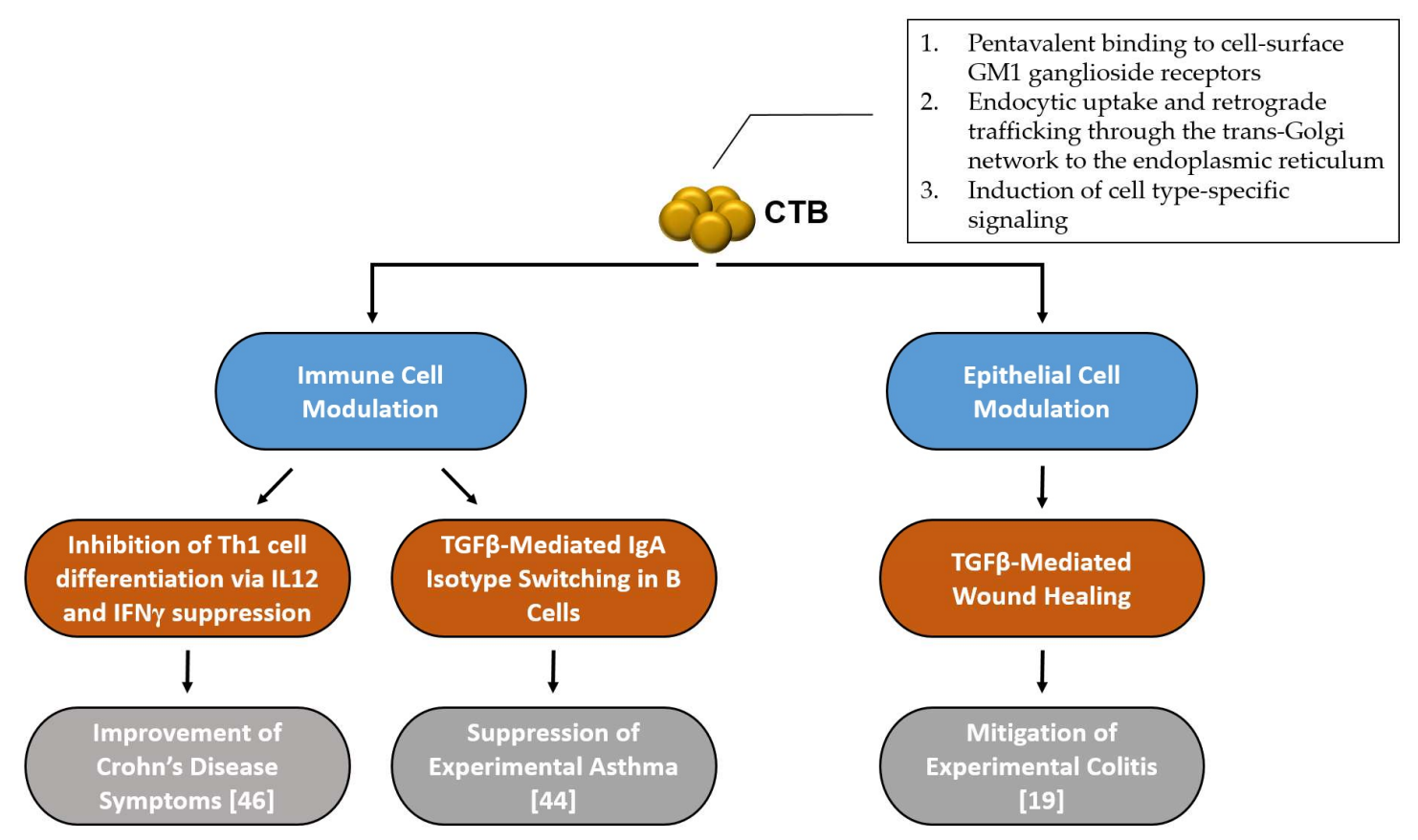

Figure 1. Summary of mechanisms involved in cholera toxin homopentameric B-subunit (CTB)'s inflammatory disease intervention. 


\section{1-2-2. A PLANT-MADE CTB VARIANT (CTBP) DIRECTLY MODULATES}

\section{EPITHELIAL CELLS}

Besides serving as a barrier lining the mucosal surface, epithelial cells have multiple functions associated with the maintenance of gut homeostasis and mucosal healing, and crosstalk between epithelial and immune cells is an important component of those complex biological processes $[58,59]$. Even though CTB first encounters epithelial cells in the gut, the CTB-mediated modulation of epithelial cells and its consequence to the mucosal immune system have largely been ignored in comparison to the protein's direct impacts on immune cells.

In one small study, CTB was shown to induce a dose-dependent increase of IL-10 mRNA levels in the colon epithelial cell-line T84 [60], hinting that CTB could induce epithelial cell-mediated immune modulation [61]. We have recently characterized CTB's global impacts on the gut to further our understanding of its unique biological activities. Using CTBp $[15,62]$, we have shown that oral administration of the CTB variant significantly altered several immune cell populations in the colon lamina propria [23]. Two-weeks after two oral $30 \mu \mathrm{g}$ CTBp administrations, Th2 and Treg cells increased in the colon lamina propria. This is not the first report of CTB-induced increase in these cell types $[19,40,42,63,64]$. For instance, it has been shown that oral administration of a CTB-insulin conjugate in NOD mice induced a shift from Th1 to Th2 profile while generating Treg cells [19]. Additionally, intraperitoneal administration of nrCTB to rats increased Treg cells in the peripheral blood 24-72 $\mathrm{h}$ after ischemia [63]. Besides the specific $\mathrm{T}$ helper cell subsets, our study has also revealed that innate immune cells- 
including dendritic cells, natural killer cells and macrophages (both M1 and M2)— populations were increased in the colon lamina propria two weeks after CTBp oral administration [23]. Furthermore, a global gene expression analysis revealed that CTBp had more pronounced impacts on the colon than the small intestine, with significant activation of TGF $\beta$-mediated pathways in the colon mucosa [23]. Given that there is a strong link between epithelial-derived TGF $\beta$ and innate immune cells in wound healing [65-67], the results provided implications for the potential utility of CTBp to promote colonic mucosal health. Subsequently, we found that CTBp induced TGF $\beta$-mediated wound healing in $\mathrm{Caco} 2$ colon epithelial cells. Furthermore, oral administration of CTBp in mice protected against colon mucosal damage in acute colitis induced by dextran sodium sulfate (DSS). Two oral doses of as low as $1 \mu \mathrm{g}$ of CTBp mitigated clinical signs of disease (body weight loss, decreased histopathological scores, and blunted escalation of inflammatory cytokine levels) and upregulated wound healing-related genes [23]. Interestingly, CTBp administration prevented fibrosis associated with acute colitis in mice; hence, the protein did not appear to overstimulate TGF $\beta$ signaling, at least under the conditions employed in the study. In fact, TGF $\beta$ gene expression levels were high during the early inflammatory phase and became lower in the recovery phase of the acute colitis model in CTBp-treated mice.

The main driver of intestinal inflammation in the DSS-colitis model is the damage to the epithelial barrier lining the colon that allows intestinal microbiota into submucosal compartments, in contrast to TNBS-induced colitis [68-72], and meanwhile the therapeutic effects were observed immediately upon CTBp administration. Therefore, we concluded that CTBp's protective efficacy in the DSS colitis models were attained by the 
induction of TGF $\beta$-mediated colonic epithelial wound healing. Given that chronic inflammation and injury of the bowel, such as inflammatory bowel disease (IBD), pose an increased risk of developing colitis-associated colorectal cancer (CAC) [73-76], CTBp's effects were also examined in the azoxymethane (AOM)/DSS mouse model of CAC. Biweekly oral administration of CTBp over 9 weeks significantly reduced inflammation and tumorigenesis in this model, highlighting its therapeutic potential in intestinal injury and inflammatory bowel disease, such as ulcerative colitis (UC) [23].

$\mathrm{UC}$ is a class of inflammatory bowel diseases (IBD), along with Crohn's disease (CD), that affects 286 per 100,000 persons ( $0.3 \%$ of total population) in the USA alone [77]. Although the etiology of UC remains elusive, genetic and environmental factors appear to trigger dysregulated mucosal immune responses, leading to the onset and progression of chronic inflammation, disrupted intestinal barrier function and epithelial damage in the colon [78]. There is no curative therapy available for UC; conventional treatment strategies aim to blunt the inflammatory response and establish remission by employing corticosteroids, aminosalicylates and immunosuppressive agents. However, these agents have limited efficacy or severe adverse reactions, often requiring additional treatment or surgical resection of the colon [79]. Studies using anti-inflammatory agents, such as anti-TNF $\alpha$ agents, have led to a general consensus that mucosal healing is the most important treatment goal in UC [80, 81]. In two randomized, double-blind, placebo-controlled studies (ACT1 and 2), there was a $\sim 5$-fold higher rate of clinical remission at week 30 in patients treated with the anti-TNF $\alpha$ infliximab who exhibited mucosal healing at week 8 than those without mucosal healing [16]. Additionally, mucosal healing was significantly associated with a lower risk of future colectomy in a 
study of 513 Norwegian patients diagnosed with UC, [17]. Collectively, it has been shown that mucosal healing is closely associated with lower incidence of relapse, improved quality of life and fewer surgical operations and cancer incidence [82-87]. However, there is no clinically approved drug that can consistently induce mucosal healing in patients. Anti-TNF $\alpha$ agents (Infliximab, Adalimumab) can achieve mucosal healing in up to half of patients $[88,89]$, as these drugs are simply anti-inflammatory agents that do not directly stimulate mucosal healing. Thus, mere inhibition of inflammatory responses does not necessarily facilitate mucosal healing. Mucosal healing is a dynamic biological process involving spatial and temporal network of mediators of different cell types including epithelial cells, resident and recruited inflammatory cells and stromal cells $[83,90]$. Development of a new drug specifically targeting mucosal healing will fill the gap in the current UC treatment paradigm.

A clear definition of mucosal healing has yet to be determined $[83,90]$. It has been inferred that mucosal healing involves the coordination of intestinal epithelial cells, goblet cells, and Paneth cells for healing of intestinal barrier function [83]. Additionally, intestinal epithelial wound repair is especially critical for mucosal healing in UC patients, because UC's pathology is limited to the mucosa unlike CD that manifest as transmural disease [83], epithelial would healing has particularly significant therapeutic implications in UC [91]. Wound repair has been extensively studied in non-mucosal tissues such as the skin have been extensively studied for their wound repair mechanism, but the same mechanism seems to be applicable to mucosae [90]; it involves 3 main overlapping phases, inflammation, proliferation and remodeling. Each phase relies on the appropriate levels of cytokines and growth factors in the wound environment [92-94]. Among these, 
TGF $\beta$ plays critical roles in the all 3 healing phases. Immediately after injury, a provisional wound matrix is formed to fill the tissue gap comprised of thrombocytes, platelets, cytokines and growth factors, such as TGF $\beta$. In the inflammation phase, TGF $\beta$ induces the recruitment immune cells such as, neutrophils and macrophages, to clean up the wound environment and subsequently regulates immune cells to resolve inflammation. Before inflammation is completely resolved TGF $\beta$ initiates a rapid migration response of the epithelial sheet (termed restitution) [95, 96]. The process occurs independently of proliferation and results in depolarization of intestinal epithelial cells surrounding the wounded area [96]. This depolarization leads to an epithelial-tomesenchymal transition (EMT) where cells adopt a migratory phenotype induced by increased TGF $\beta$ levels $[97,98]$. In the proliferation phase, TGF $\beta$ promotes angiogenesis, fibroblast proliferation and production of extracellular matrix (ECM) components, which leads to reepithelialization and restoration of the mechanical strength of the wound. Lastly, in the remodeling phase, TGF $\beta$ contributes to ECM remodeling by regulating the expression of various enzymes including matrix metalloproteinases (MMPs) and tissue inhibitors of MMPs (TIMPs) [83, 90, 92, 93, 99]. Importantly, TGF $\beta$ can be a doubleedged sword in mucosal remodeling; while TGF $\beta$ has beneficial effects during the early stage of wound healing, it can promote scar formation and fibrosis at the late stage [92, 100]. Also, although TGF $\beta$ functions as a suppressor of epithelial cell tumorigenesis at an early stage of tumor development, its expression is correlated with tumor progression and poor prognosis at late stages [100]. Thus, a tight control of TGF $\beta$ signaling, when targeted to induce mucosal healing in UC, is critical, because UC poses an increased risk of developing colitis-associated colorectal cancer (CAC) [73, 74]. Given that mucosal inflammation of IBD reflects composite conditions including both nascent and 
established inflammations [101]. it is likely that TGF $\beta$-mediated wound repair remains to play a significant role at least in some parts of UC colon mucosa. Therefore, the finding that CTBp is a topical agent that facilitates TGF $\beta$-based mucosal wound healing in UC and CAC mouse, supports a hypothesis that CTBp could help address important issues pertinent to therapeutic strategies for mucosal healing in UC.

It is of importance to point out that many of the effects observed in the aforementioned studies using CTBp may be unique to the plant-made variant, as it has a mutation at amino acid position 4 and an ER retention signal sequence at the $\mathrm{C}$-terminus (N4S-CTB-SEKDEL; [62]). The ER-retention sequence was added to CTBp to improve production in planta, while Asn $4 \rightarrow$ Ser mutation was introduced to avoid $N$-glycosylation $[15,62]$. The addition of the KDEL sequence to N4S-CTB significantly reduced ER stress that otherwise caused poor production yield. It is thought that the KDEL sequence helped prolong CTBp's residence time in the ER to allow for proper folding and assembly.

The protein ER retention mechanism involving the KDEL receptor is highly conserved among eukaryotic organisms [102]. Thus, there is a possibility that the artificial KDEL sequence of CTBp may prolong the protein's residence in the epithelial cells upon binding to cell-surface GM1 ganglioside and retrograde transport into the ER, as has been demonstrated for CT [25, 27].

Regardless of whether the ER retention signal had a significant contribution to the mucosal healing activity in the mouse colitis models, the study has provided evidence 
that CTB can exhibit a therapeutic effect against colitis in an epithelia-dependent manner, warranting further investigation of CTB's impacts on epithelial cells.

The overall goal of this project is to develop CTBp as a biotherapeutic to facilitate mucosal healing in UC patients. To that extent, the objective of this thesis is to investigate how CTBp's C-terminal KDEL sequence contributes to the protein's mucosal healing activity in vivo, in vitro, and ex vivo. To achieve this goal I formed three specific aims. First, I aimed to determine if the CTBp-mediated reduction of colitis we previously reported was unique to the KDEL-tagged protein in a mouse model of DSS-colitis [23]. Second, I investigated if CTBp's epithelial healing activity, intracellular retention, and signaling pathways were affected by the protein's KDEL sequence using a series of CTBp and rCTB analogues. Lastly, I aimed to determine if CTBp's KDEL sequence contributes to the protein's translational efficacy using a UC patient colon tissue explant.

Collectively, the research in this thesis characterized CTBp's colon mucosal healing efficacy, mechanisms, and translatability at cellular and molecular levels, supporting the development of CTBp as a new topical UC drug. Furthermore, this thesis discloses previously undescribed impacts of $\mathrm{rCTB}$ and its derivatives on colon epithelial cells, providing new information to the fields of mucosal immunology and pathophysiology. 


\section{MATERIALS AND METHODS}

Animals. Eight-week-old C57BL/6J female mice were obtained from Jackson Laboratories (Bar Harbor, ME). Animal studies were approved by the University of Louisville's Institutional Animal Care and Use Committee.

Study design. CTBp was produced in N. benthamiana and purified to $>95 \%$ homogeneity with an endotoxin level of $<1$ endotoxin units per $\mathrm{mg}$, as described previously[62]. For all animal experiments, 10 mice per group, randomly assigned, were used. For the acute DSS recovery model of intestinal injury, DSS exposure was initiated on the day mice turned 9 weeks old (day 0), using a modified method[23]. Body weights were measured at the initiation of DSS exposure as a baseline and every morning thereafter to determine percent change. Animals received 3\% DSS (M.W. 36,000 to 50,000; MP Biomedicals, Santa Ana, CA) in drinking water for 7 days. On the $7^{\text {th }}$ day of DSS exposure, animals gavaged with PBS or CTBp after sodium bicarbonate administration, as described previously [62], and allowed to recover 7 days during which the animals received normal drinking water.

Immunohistochemistry. Colons were removed and washed with PBS. A portion of the distal colon was fixed with paraformaldehyde overnight and stored in $70 \%$ ethanol until paraffin embedding and sectioning. Sections were deparaffinized with Citrisolv and 
rehydrated through several ethanol washing steps ending with incubation in distilled water. Antigen retrieval was performed overnight with a 2100 Retriever (Electron Microscopy Sciences) using a pH 6.0 buffer. Tissue sections were blocked for endogenous peroxidase, avidin, biotin, and serum from the animal in which the secondary antibody was raised. Primary antibody (anti-E cadherin; Abcam) was incubated with the tissue sections for $1 \mathrm{~h}$ at room temperature. The Vectastain Elite ABC kit (goat antirabbit; Vector Labs, Burlingame, CA) was used to label the primary antibody. Ecadherin + cells were visualized with the ImmPACT DAB Substrate Kit (Vector Labs) and then dehydrated through an ethanol gradient and finally incubated with Citrisolv. Sections were scanned using an Aperio ScanScope CS (Leica Biosystems, Buffalo Grove, IL) $n=10$ representative sections (40x magnification) from each colon.

RNAisolation. Sections from the distal colon were stored in RNAlater (Qiagen, Valencia, CA) at $-20^{\circ} \mathrm{C}$ until RNA was isolated. Colon tissue $(\sim 14 \mathrm{mg})$ was placed in QIAzol lysis reagent and homogenized. An RNeasy Microarray Tissue Kit from Qiagen was used to purify the RNA from the tissue homogenate. RNA concentration, quality, and purity was confirmed by spectrophotometer then stored at $-80^{\circ} \mathrm{C}$ until use.

qRT-PCR. First strand cDNA was obtained from reverse transcription of 100 ng RNA using a SUPERSCRIPT VILO cDNA synthesis kit (Life Technologies, Carlsbad, CA) according to the manufacturer's instructions. Template cDNA were added to a reaction mixture containing $\mathrm{RT}^{2}$ SYBR Green Master Mix (Qiagen) and loaded in $\mathrm{RT}^{2}$ Profiler PCR Array Standard 96 well Plates (Qiagen). These plates contain pre-spotted individual gene expression probes for the detection of genes of interest as well as the house keeping 
genes 18S, b-actin (ACTB), and GAPDH. PCR amplification was carried out on a 7500HT Fast Real-Time PCR System (Applied Biosystems) with the following conditions: 95 1C, $20 \mathrm{~min}$; 40 cycles (95 1C, $1 \mathrm{~min}$ ); $20 \mathrm{~min}$ at $601 \mathrm{C}$. The 7500 Software v2.0.6 (Applied Biosystems) was used to determine the cycle threshold $(\mathrm{Ct})$ for each reaction and derive the expression ratios relative to control. Wound healing pathway analysis was performed with a RT2 Profiler PCR Mouse Wound Healing Array (Qiagen, Manchester, UK) under the same conditions described above.

Flow cytometry. Flow cytometry was used to assess the binding of rCTB and CTBp molecules to Caco2 cells, according to a well-established procedure [14]. Briefly, 10 $\times 10^{5}$ cells were seeded in EMEM (serum free) in the presence of $1 \mu \mathrm{M}$ rCTB or CTBp and incubated for 15 minutes on ice. Next, cells were washed and blocked with 3\% BSA (Sigma) on ice. Then cells were exposed to monoclonal antibody 9F9C7, which was produced from a rat hybridoma cell line, for $1 \mathrm{~h}$ at room temparature and washed before incubation with a rabbit Alexa Fluor ${ }^{\mathrm{TM}} 488$ anti-rat $\operatorname{IgG}(\mathrm{H}+\mathrm{L})(\mathrm{A} 21210$, Life Technologies, Eugen, OR) for $1 \mathrm{~h}$ on ice. Finally, cells were washed and analyzed with a FACSCalibur (Becton Dickinson), counting 10,000 cells per sample. Data were acquired BD FACSCanto II and analyzed with FLOWJO v10 data analysis software, using PBS as a negative control $(n=4)$.

Caco2 wound healing assay. The Caco2 wound healing assay was performed as previously described [23]. Briefly, the cells were seeded and grown in complete growth medium (EMEM + 20\% FBS, 1x penicillin-streptomycin) to confluence in 6 well plates (Thermo Scientific Nunc Cell-Culture Treated, Roskilde, Denmark). The culture medium 
was discarded, two $0.5-1.0 \mathrm{~mm}$ across linear wounds were made per well with a $200 \mathrm{~mL}$ sterile beveled pipette tip (USA Scientific, Enfield, CT) and cells were washed with PBS. PBS, rCTB, CTBp, CTB-KDE, or eCTBp (0.1-10 $\mu \mathrm{M})$, TGFb1 (0.2 nM; Abcam, Cambridge, MA), and/or $4 \mu 8 \mathrm{C}(0.5 \mu \mathrm{M}$; MilliporeSigma, Burlington, MA) were subsequently added in fresh serum-deprived medium. Photomicrographs of the wounds were taken 0,24 , and $48 \mathrm{~h}$ after the wounding at $4 \mathrm{X}$ magnification. Quantification of the remaining cell-free area to the initial wound area was measured using the public domain software Image $\mathrm{J}$ (http://rsbweb.nih.gov), and calculated as a mean percentage ( $\mathrm{n}=2$ experimental replicates) per well. The culture medium/supernatants were collected from each well 24 or $48 \mathrm{~h}$ after wounding and stored at $-80^{\circ} \mathrm{C}$ until analysis. The culture supernatants were analyzed by a human Cytokine/Chemokine or TGFb1, 2, 3 Magnetic Bead Panel (EMD Millipore, St. Charles, MO). The panel was analyzed with a Milliplex MAP Kit on a MagPix with Luminex xMAP technology. Each experiment was performed with 4 biological replicates per construct $(n=4)$.

Caco2 cell immunofluorescence. Cells were seeded 2 x $10^{5}$ cells/well in Lab-Tek II chamber slides (Thermo, Rochester, NY) and grown for 72 hours in complete growth medium. The media was subsequently removed and cells were washed with PBS followed by PBS, rCTB, or CTBp $(1 \mu \mathrm{M})$ treatment in fresh serum-deprived medium. Cells were incubated for 6 or 24 hours at $37^{\circ} \mathrm{C}$ in a humidified $5 \% \mathrm{CO} 2$ then fix, permeabilized, and stained according to the ER staining kit (ab139482, Abcam) manufacturer's protocol. Briefly, after treatment cells were washed with PBS and fixed/permeabilized using cold methanol/acetone (2:1) for 15 minutes. Cells were then blocked (3\% BSA, Sigma) and treated with a rat anti-CTB mAb (1:1000) for 1 hour at 
RT. After subsequent washing (PBS), a rabbit Alexa Fluor ${ }^{\mathrm{TM}} 488$ anti-rat $\operatorname{IgG}(\mathrm{H}+\mathrm{L})$ (A21210, Life Technologies, Eugen, OR) was applied to cells for 1 hour at RT followed by additional washing (PBS). A ER-selective dye (ab139482) was then added (1:1000) for 15 minutes at $37^{\circ} \mathrm{C}$ followed by washing (PBS) and mounting with coverslip using mounting medium for fluorescence with DAPI (VECTASHIELD $\AA$, Burlingame, CA). Slides were analyzed by wide-field fluorescence confocal microscope (60x magnification, Z-stacked images). Localization and co-localization statistical analysis was performed using Imaris software (Bitplane), values were calculated in voxels

\section{Treatment and culturing of colon explants obtained from ulcerative colitis patients.}

The treatment and culturing of colon explants was performed using an immersion culturing system developed from a previously described methods [50, 103, 104]. Rectal tissues were obtained from consenting patients at the time of colectomy. Immediately after excision, colectomy tissue was placed in complete medium (RPMI 1640 supplemented with $2 \mathrm{mM}$ L-glutamine, $10 \mathrm{mM}$ HEPES buffer, $10 \mu \mathrm{g} / \mathrm{ml}$ gentamicin, 100 $\mathrm{U} / \mathrm{ml}$ each of penicillin and streptomycin, and 10\% FBS (Hy-Clone)) on ice and transported to the lab. The tissue was immediately divided and placed in organ culture dishes at $37^{\circ} \mathrm{C}$ in a humidified $5 \% \mathrm{CO} 2$. The tissues were placed luminal side up in $2 \mathrm{ml}$ complete growth medium. Cultures were incubated with or without the addition of PBS, rCTB, or CTBp $(1 \mu \mathrm{M})$ at $37^{\circ} \mathrm{C}$ for 24 hours. Thereafter, the supernatant were collected, aliquoted and stored at $-80^{\circ} \mathrm{C}$, tissues were washed in complete medium and homogenized for gene expression analysis, formalin-fixed for histopathology, or frozen in liquid nitrogen for additional analysis as necessary. 
Statistics. For all data, outliers were determined by statistical analysis using the Grubb's test $(\mathrm{P}<0.05)$ and excluded from further analysis. Graphs were prepared and analyzed using Graphpad Prism version 5.0 (Graphpad Software, La Jolla, CA). To compare two data sets, an unpaired, two-tailed Student's $t$ test was used. To compare three or more data sets, one-way ANOVA with Bonferroni's multiple-comparison post-test or KruskalWallis test with Dunn's multiple comparison post-test were performed. For body weights and DAI results, a two-way ANOVA with Bonferroni's multiple-comparison post-test was employed. A $P$ value of $<0.05$ was considered significant. 


\section{RESULTS}

\subsection{CTBP UNIQUELY MITIGATES DSS-INDUCED ACUTE COLONIC INJURY AND INFLAMMATION}

To the best of our knowledge, no studies have reported rCTB effects in a mouse DSSinduced colitis model. Thus, to determine if the wound healing effects that we reported previously for CTBp are unique to the plant-made variant, we employed a wellestablished mouse DSS colitis model [23]. Administration of DSS to mice in their drinking water for 5-7 days results in the induction of chronic inflammation in the colon and multiple histological changes characterized by erosions/ulcers of the epithelia, loss of crypts, and infiltration of leukocytes $[105,106]$. In this study, female C57bl/6 mice were given one dose of PBS, $3 \mu \mathrm{g}$ CTBp, or $3 \mu \mathrm{g}$ rCTB via gavage after a 7 -day $3 \% \mathrm{DSS}$ exposure period (Day 7), at which the onset of colonic epithelial damage had taken place [70]. As shown in Figure 2A, CTBp-dosed mice showed a significantly more rapid recovery from DSS-induced weight loss than PBS and rCTB-dosed groups. This trend was noted as early as 3 days post administration (Day 10) in CTBp-dosed mice. The recovery in body weight was accompanied by a significant protection from colon shrinkage, as well as significant decrease in disease activity index (DAI) scores (Figure 2B). Histopathological examination on hematoxylin and eosin (H\&E)-stained distal colon tissue 7 days post DSS exposure (Day 14) revealed that CTBp treatment protected mice from ulceration, inflammation and loss of colonic epithelial surface and crypts as shown by an inflammatory score, in contrast to PBS and $\mathrm{rCTB}$ treatment (Figure 2B). These data were supported by immunohistochemistry (IHC) staining for an epithelial marker, E- 
cadherin $[107,108]$, on the same tissues used for histopathological examination. The IHC analysis clearly revealed that CTBp-treated mice had an epithelial surface that has recovered (or maintained) near-normal morphology and thickness with ongoing crypt regeneration noted throughout the tissue (Figure 3). Consistent with these findings, a RTqPCR analysis revealed that CTBp administration significantly upregulated multiple genes associated with epithelial repair, including Cdh1, Wnt5a, Vegf and Col5a3 (Figure 2C) [109-112]. Furthermore, a complete blood count analysis of terminal blood samples (collected on Day 14) showed that CTBp treatment significantly reduced the DSSinduced escalation of monocyte, basophil and eosinophil levels compared to PBS-dosed mice. Neutrophil levels were significantly higher in PBS and rCTB-dosed mice compared to those of the healthy control animals, but not in CTBp-dosed animals (Figure 2D). Collectively, these results suggest that the ability to mitigate DSS-colitis and induce wound healing in mouse colons is unique to the plant-made variant. 

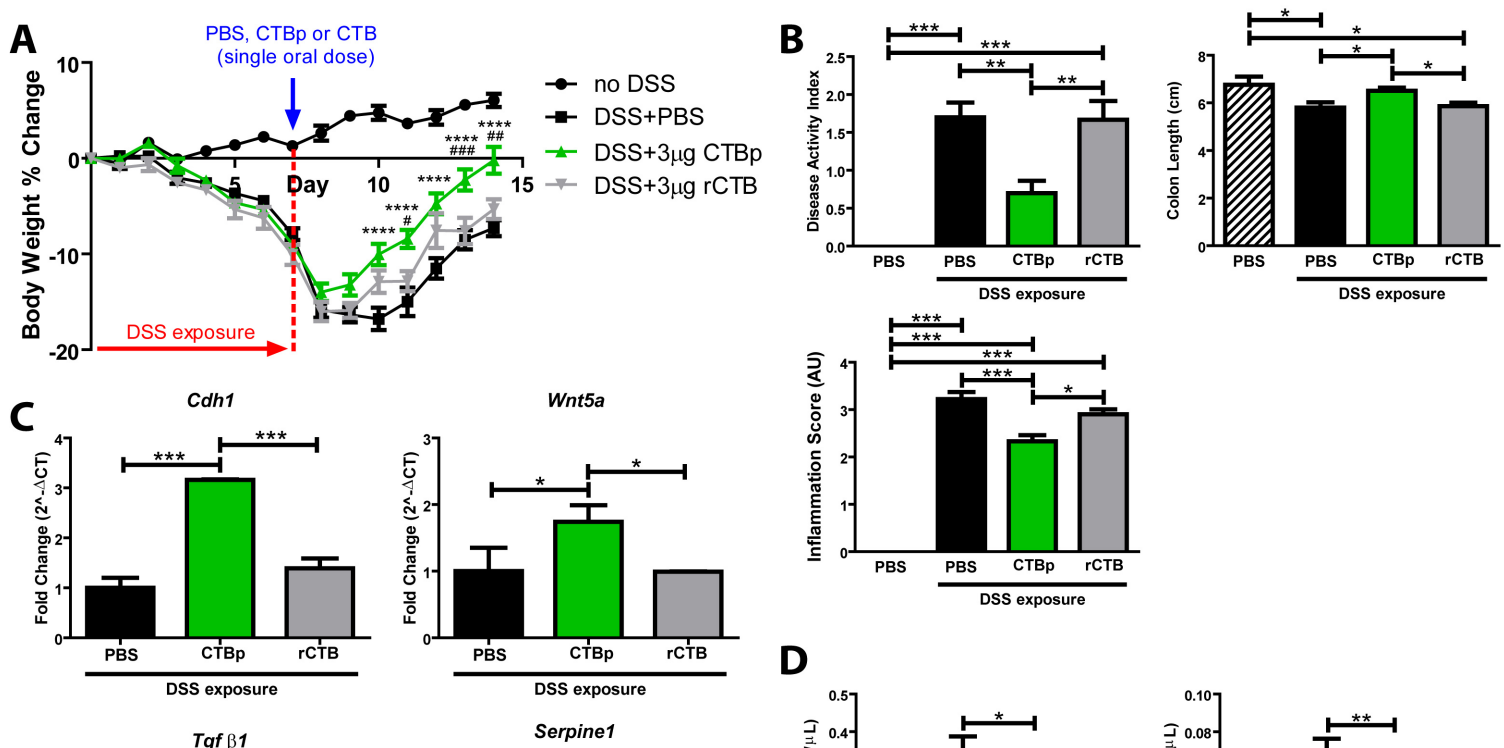

D
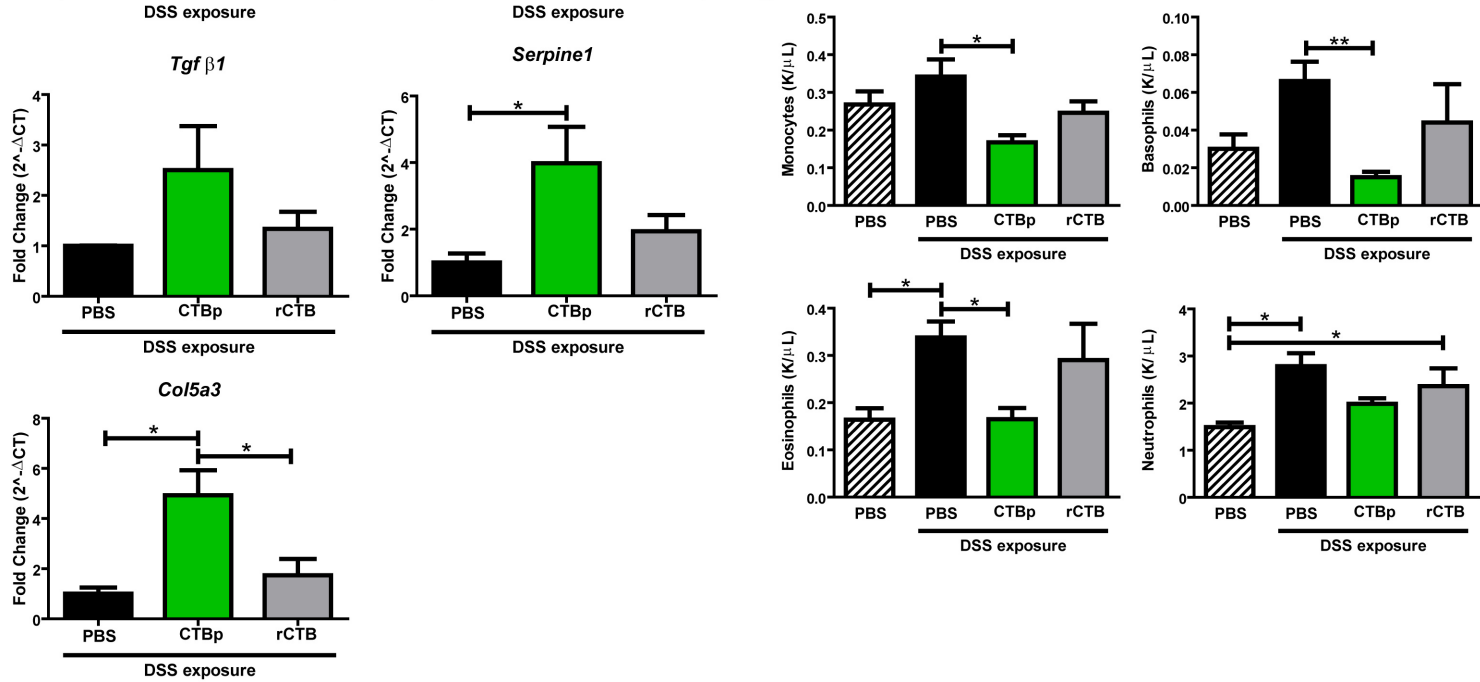

Figure 2. Effects of orally administered rCTB or CTBp in an acute DSS-colitis

model. Mice (female C57BL/6J, 9-week old) were exposed to 3\% DSS for seven days and orally administered with PBS, rCTB, or CTBp on the 7 seventh day. Colon tissues were isolated after a 7-day recovery for analyses. Mean \pm s.e.m. is shown for each group. $\mathrm{N}=10$ Animals per group. (a) Percent change of body weights. Animals were weighed daily and just prior to the initiation of DSS exposure. Percent change was based on the initial body weight. $* \mathrm{P}<0.05$ between DSS-exposed, CTBp and PBS-administered groups, \# $\mathrm{P}<0.05$ between DSS-exposed, CTBp and rCTB-administered groups; twoway ANOVA with Bonferroni's multiple comparison tests. (b) Top-left: Disease activity 
index (DAI) scores calculated from body weight loss, fecal consistency and occult blood scores at the time of sacrifice. Bottom-left: Colon inflammation scoring from paraffin embedded tissue sections were scored after staining with Hematoxylin and Eosin (H\&E). Scoring was based on 0-4 scale. Top-right: Colon length. (c) qRT-PCR analysis of cytokine gene expression in mouse colon tissue. Mean \pm s.e.m. is shown for each group $(\mathrm{N}=4)$. (d) Complete blood count analysis performed at the time of sacrifice. Mean \pm s.e.m. is shown for each group ( $\mathrm{N}=5)$. Bonferroni's multiple comparison tests was used to compare all pairs of groups (a, b, c, d). Significantly different pairs are highlighted with asterisks $\left(* \mathrm{P}<0.05,{ }^{*} \mathrm{P}<0.01\right.$, and $\left.* * * \mathrm{P}<0.001\right)$.

To reveal any potential gender specific differences in the aforementioned findings, we employed a DSS-induced colitis model using male mice. Since male mice are more sensitive to DSS-induced colitis, a lower concentration of DSS $(2.5 \% \mathrm{w} / \mathrm{v})$ was used [113]. In this experiment, mice were dosed in the same manner as in figure 1. Unlike female mice, CTBp-dosed male mice did not show a drastic effect in recovery from DSS-induced weight loss (Figure 4A), likely due to the low $3 \mu \mathrm{g}$ dose not being able to overcome a combination severity of colitis and increased size of the male mice. In this study, healthy male mice weighed $\sim 10 \mathrm{~g}$ more than healthy females and healthy male colon lengths were on average $1.28 \mathrm{~cm}$ longer than healthy females. Nonetheless, CTBp treatment provided a significant protection from colon shrinkage, as well as significant decrease in DAI scores (Figure 4) in contrast to PBS and rCTB-dosed groups. Therefore, these results suggest that CTBp's ability to uniquely mitigate DSS-colitis is not limited to female mice although the therapeutic window may be different. 
A. PBS
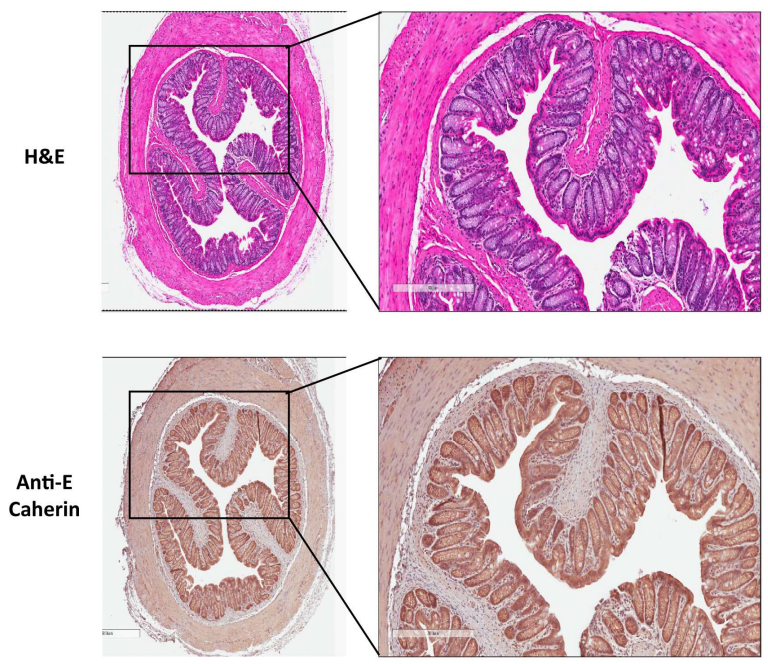

B. PBS DSS
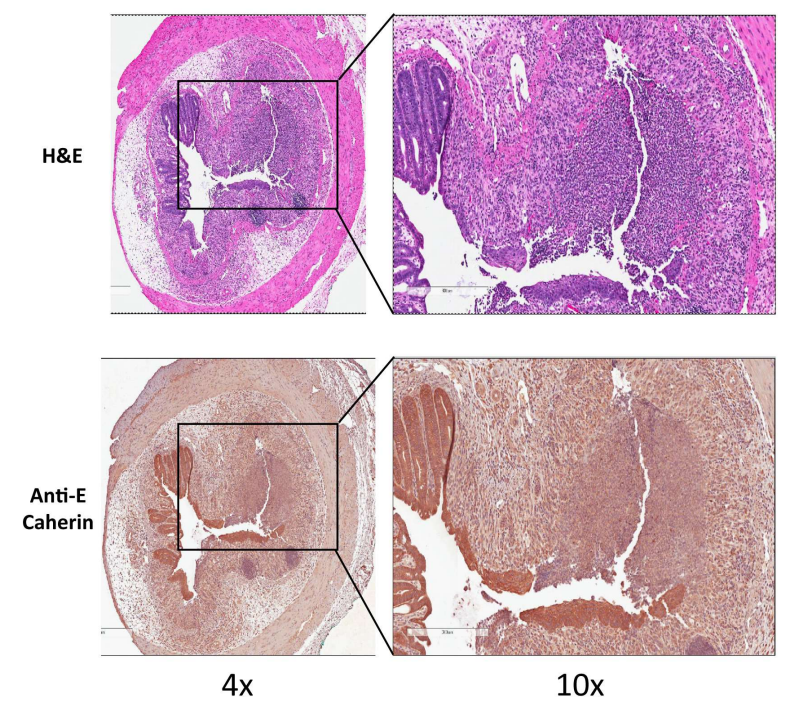

C. CTBp DSS
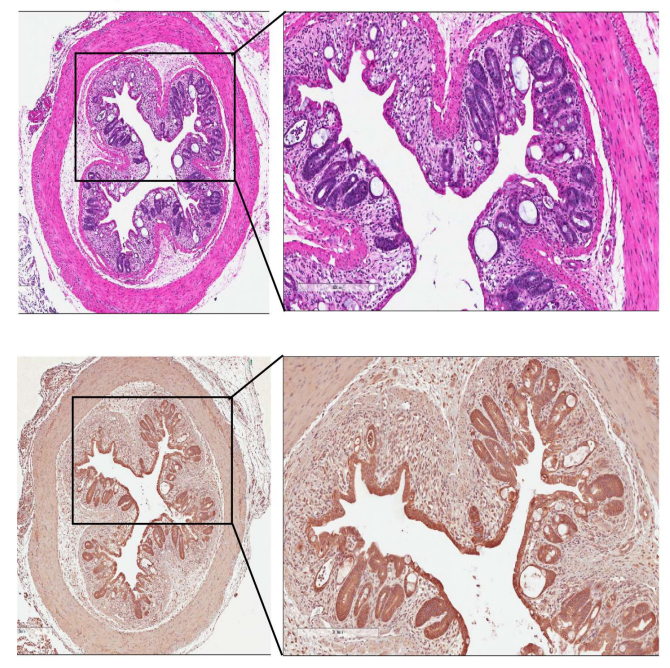

D. rCTB DSS
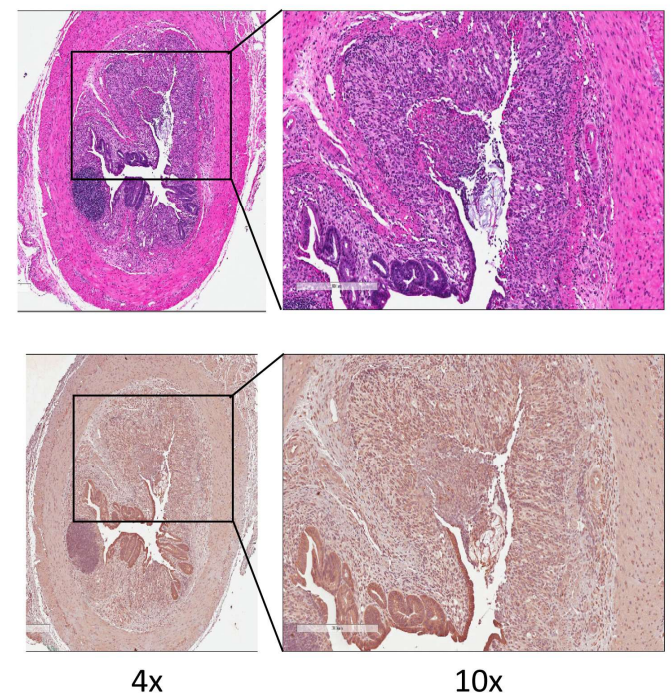

Figure 3. CTBp and $\mathrm{rCTB}$ effects on mouse colon histological alterations induce by

DSS-colitis. CTBp treatment protected mice from ulceration, inflammation and loss of

colonic epithelial surface and crypts. (a, b, c, d) Top: representative 4x (left) and 10x (right) photomicrographs of H\&E stained distal colon tissues from each group from treatment groups. Bottom: Immunohistochemistry staining of E-cadherin positive cells in distal colon tissue, representative photomicrographs are shown. 


\subsection{CTBP UNIQUELY ENHANCES WOUND CLOSURE AND TGFB LEVELS IN}

HUMAN COLONIC EPITHELIAL CELLS.

To contrast the previously described wound healing ability of CTBp with that of $\mathrm{rCTB}$, we employed a human colon epithelial cell line Caco2 model of wound healing [23]. As shown in Figure 5B, 0.1-10 $\mu \mathrm{M}$ CTBp significantly enhanced wound healing 24 hours post-wounding with no apparent dose response relationship, while rCTB had no effect at the same concentrations tested. Additionally, wound closure over 48 hours was tested using $3 \mu \mathrm{M}$ of CTBp, rCTB, or PBS. The results revealed that $\mathrm{rCTB}$ had no effect beyond the natural healing response noted in the PBS-treated group, while CTBp treatment significantly enhanced wound closure both at 24 and 48 hours post wounding (Figure 5C). To dissect the wound healing response further, TGF $\beta$ levels in the culture supernatants were measured using a multiplex bead array. In contrast to $\mathrm{rCTB}, \mathrm{CTBp}$ significantly upregulated TGF $\beta 1$ and TGF $\beta 2$ levels 24 hours post-wounding (Figure 5D). To rule out if the difference observed between CTBp and $\mathrm{rCTB}$ was the result of differential binding to $\mathrm{Caco} 2$ cells, we performed a flow cytometry analysis where $\mathrm{Caco} 2$ cells were treated with $1 \mu \mathrm{M} \mathrm{CTBp}$ or rCTB. Cells were treated for 15 minutes on ice then fixed and stained with an anti-CTB monoclonal antibody. Both CTBp and rCTB showed high and similar binding, with $>75 \%$ of Caco 2 cells showing positive (Figure 5E). Together, these results indicate that CTBp uniquely influences TGF $\beta$ regulation in colon epithelial cells and subsequently induces epithelial wound healing at the concentrations tested. 

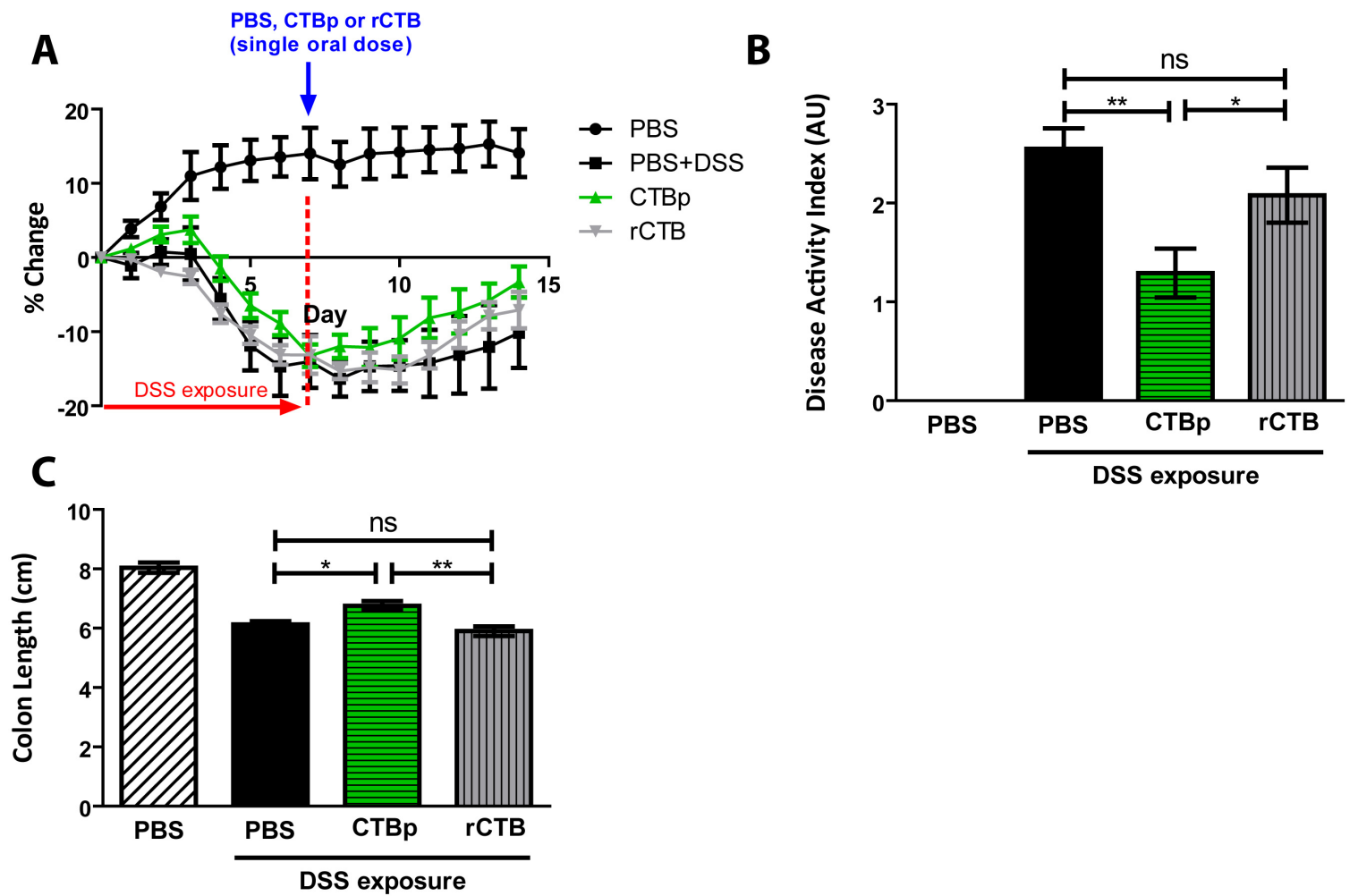

Figure 4. CTBp's in vivo activity in DSS-induced colitis is not gender specific. Mice (male C57BL/6J, 9-week old) were exposed to 3\% DSS for seven days and orally administered with PBS, rCTB, or CTBp on the 7 seventh day. Colon tissues were isolated after a 7-day recovery for analyses. (a) Percent change of body weights. Animals were weighed daily and just prior to the initiation of DSS exposure. Percent change was based on the initial body weight. No significant difference between groups, two-way ANOVAwith Bonferroni's multiple comparison tests. (b) Disease activity index (DAI) scores calculated from body weight loss, fecal consistency and occult blood scores at the time of sacrifice. (c) Colon length. Mean \pm s.e.m. is shown for each group $\mathrm{N}=10$. Bonferroni's multiple comparison tests was used to compare all pairs of groups $(\mathbf{a}, \mathbf{b}, \mathbf{c})$. Significantly different pairs are highlighted with asterisks $(* \mathrm{P}<0.05, * * \mathrm{P}<0.01$, and $* * * \mathrm{P}<0.001)$. 


\subsection{THE C-TERMINAL KDEL SEQUENCE IS ESSENTIAL FOR THE COLON EPITHELIAL WOUND HEALING OF CTBP}

The above results led us to hypothesize that the $\mathrm{C}$-terminal KDEL sequence is essential to CTBp's wound healing ability. First, in order to rule out the possibility that the unique activity is not attributed to the Nicotiana benthamiana production system, CTBp was produced in E. coli and tested in the Caco2 cell wound healing assay. Indeed, E. coliproduced CTBp significantly promoted wound healing 24 hours post-wounding in contrast to rCTB, which was also produced in E. coli. (Figure 6A) To further delineate the importance of the $\mathrm{C}$-terminal KDEL sequence, a variant of CTBp lacking the $\mathrm{C}$ terminal Leu residue (CTB-KDE; Table 1) was made. As demonstrated by Caco2 cell wound healing assay, CTB-KDE at 0.1 and $1 \mu \mathrm{M}$ failed to promote wound healing unlike CTBp (Figure 6B). 

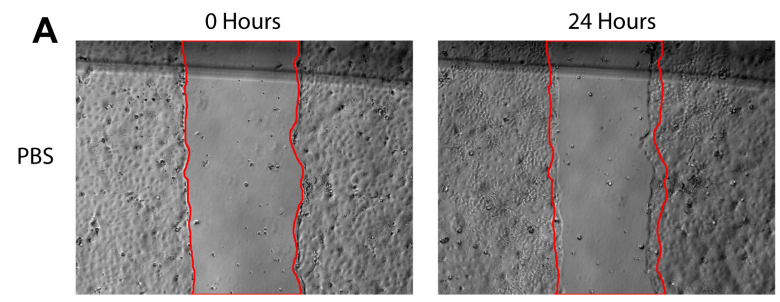

B
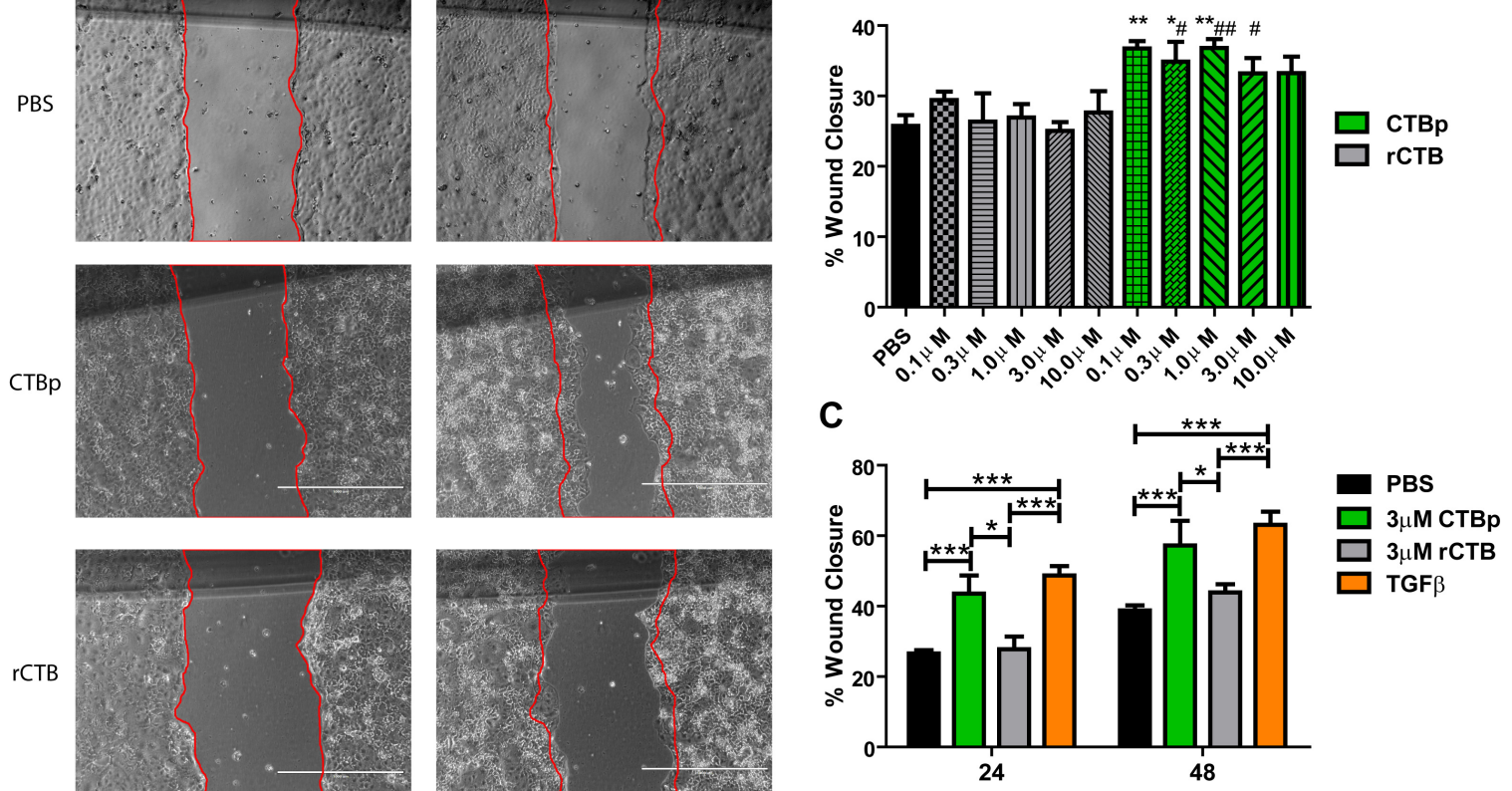

D
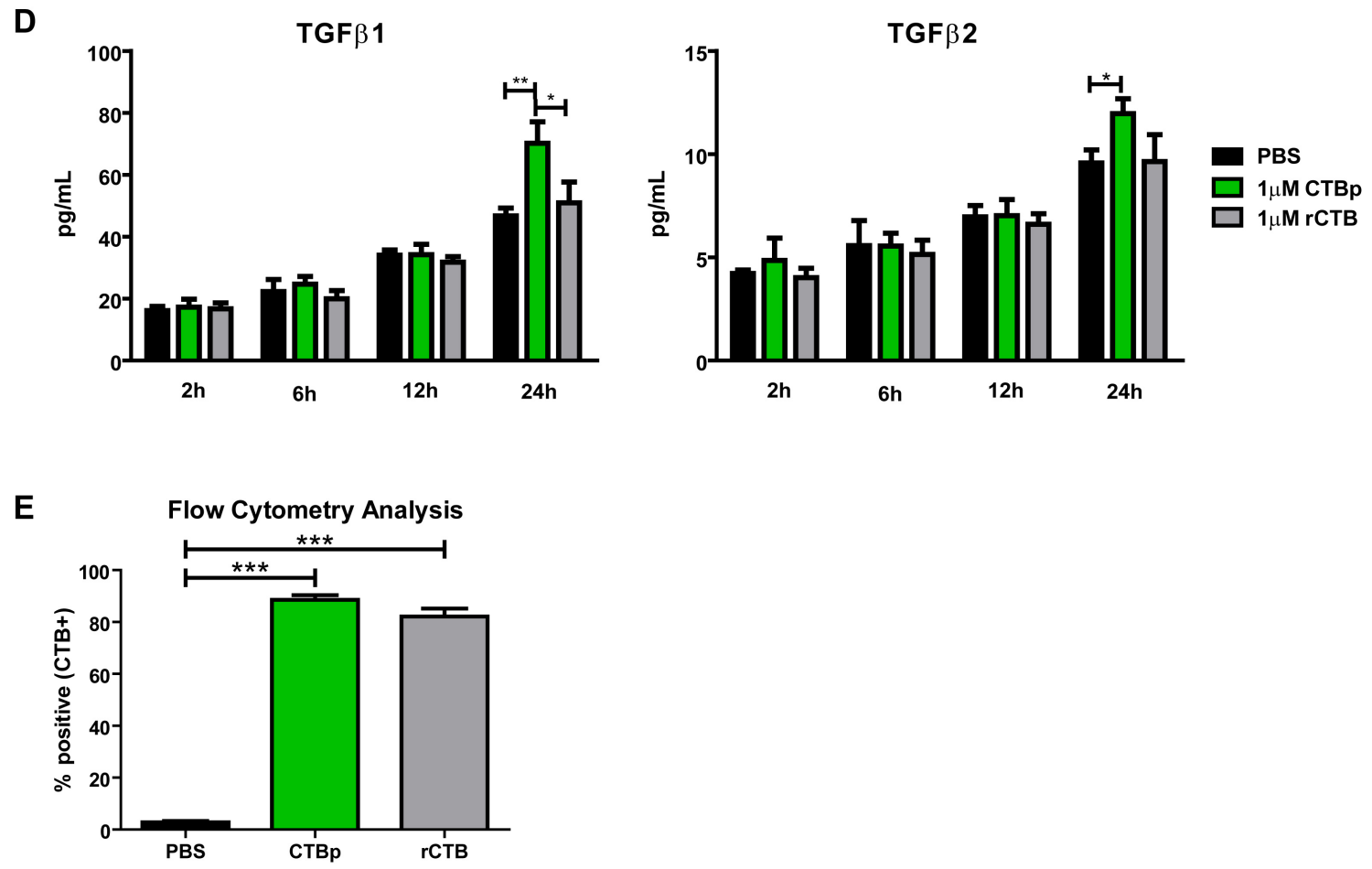

Figure 5. CTBp, but not rCTB, enhances wound healing and TGF $\beta$ levels in a human colon epithelial cell wound healing model. Caco2 cells were grown to confluence and scratched with a pipette tip. Cells were then incubated with PBS, rCTB, 
CTBp, or TGFb1. The in vitro wound closure was recorded over $48 \mathrm{~h}$ and $4 \mathrm{x}$ magnification images were acquired with a EVOSfl (Advanced Microscopy Group) and mean percentage closure was determined by Image J software. (a) Photomicrographs of wounded Caco2 cells. (b) Analysis of in vitro wound closure after $24 \mathrm{~h}$ by wound area measurement. (c) Analysis of in vitro wound closure over $48 \mathrm{~h}$ by wound area measurement. (d) Protein concentrations in Caco2 cell supernatants. (e) Caco2 cell flow cytometry analysis. $10.0 \times 10^{5}$ cells were treated with $1 \mu \mathrm{M}$ PBS, rCTB, or CTBp for 15 minutes on ice, then fix and stained with anti-CTB mAb. Means \pm s.e.m. (b, c, d, e). One-way ANOVA with Bonferroni's multiple comparison tests was used to compare all pairs of groups (b, c, d, e). Significantly different pairs are highlighted with asterisks (*P $<0.05, * * \mathrm{P}<0.01$ and $\left.{ }^{* * *} \mathrm{P}<0.001\right)$.

We next explored if the KDEL sequence of CTBp has any influence on the protein's residence within epithelial cells. Due to the known function of KDEL receptors (KDELR) [114-117], it was hypothesized that CTBp could localize and remain in the ER after retrograde transport [27]. To test this hypothesis, we utilized confocal microscopy to visualize where CTBp or $\mathrm{rCTB}$ reside within Caco2 cells. Cells were treated with 1 $\mu \mathrm{M}$ CTBp or rCTB for 6 or 24 hours and then fixed and stained for CTB, the ER, and nuclei (Figure 7A). As depicted in Figure 7B, CTBp was detected much more prevalently inside Caco2 cells with 171,083 and 190,433 positive voxels calculated to be in the imaged cells at 6 and 24 hours, respectively. In sharp contrast, rCTB had 90 and 41 positive voxels at 6 and 24 hours post treatment, respectively. Additionally, a colocalization analysis using the Z-stacked images demonstrated that $89.6 \%$ and $41.6 \%$ of CTBp at 6 and 24 hours, respectively, colocalized within the ER of the Caco 2 cells 
(Figure 7C). Of the low amount of $\mathrm{rCTB}$ within the cells only $0.26 \%$ and $0.16 \%$ at 6 and 24 hours post treatment, respectively, colocalized within the ER. Since CTBp and rCTB showed similar binding to Caco2 cells (Figure 5E), it is likely that the striking difference in their amounts detected within Caco2 cells occurred after internalization. These results were confirmed by immunoblot analysis of Caco 2 cells treated with CTBp or CTB for 0 , 12, 24 hours. CTBp showed constant existence within Caco2 cells after treatment and as expected, whereas rCTB showed decreasing levels over a 24 hour period (Figure 6C).

Thus, these results suggest that the KDEL sequence on CTBp may have interacted with KDELR inside the cell, resulting in prolonged presence in the ER.

A

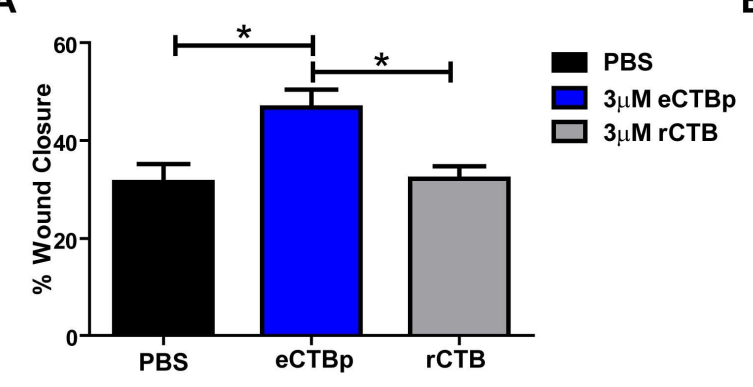

C

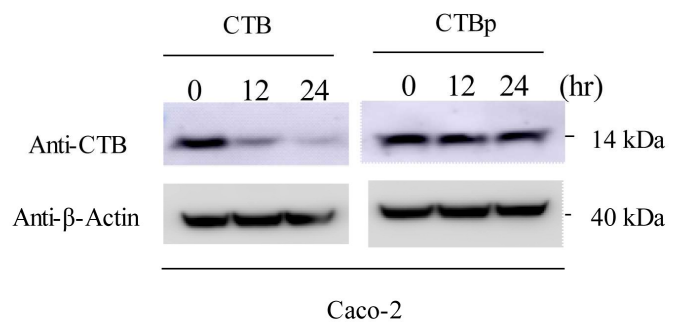

B

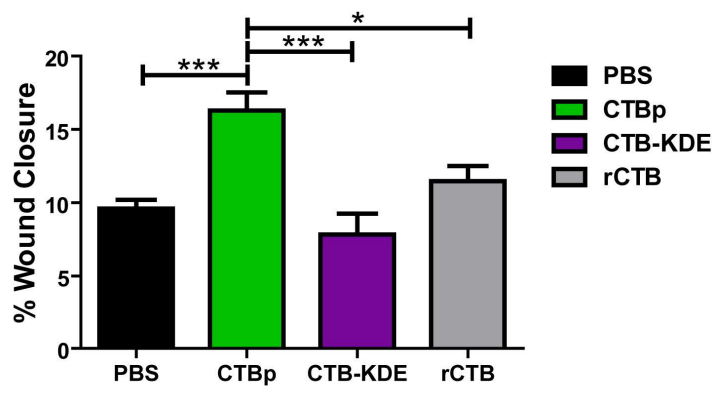

Figure 6. Analysis of CTB variants on human colon epithelial cells. Caco 2 cells were grown to confluence and scratched with a pipette tip. Cells were then incubated with PBS, rCTB, CTBp, or E. coli produced CTBp (eCTBp; Table 1)). The in vitro wound closure was recorded over $24 \mathrm{~h}$ and $4 \mathrm{x}$ magnification images were acquired with an EVOSfl (Advanced Microscopy Group). Mean percentage closure was determined by Image $\mathrm{J}$ software. (a, b) Analysis of in vitro wound closure after $24 \mathrm{~h}$ by wound area 
measurement. (c) Representative Western blot analysis of the stability of rCTB and CTBp in caco-2 cells. After a 4 hours incubation with $2 \mu \mathrm{M}$ of rCTB or CTBp, caco-2 cells were washed with EMEM, then gathered and lysed depending on a various time manner $(0,12,24$ hours $)$. $\mathrm{CTB}$ and CTBp were detected by anti-CTB mAb western blot analysis and anti-actin antibody was used for actin detection. Means \pm s.e.m. $n=4(a, b)$. One-way ANOVA with Bonferroni's multiple comparison tests was used to compare all pairs of groups $(a, b)$. Significantly different pairs are highlighted with asterisks $(* \operatorname{Po} 0.05, * * \operatorname{Po} 0.01$ and $* * * \operatorname{Po} 0.001)$.

\subsection{CTBP INDUCES AN UNFOLDED PROTEIN RESPONSE AND IRE1-XBPI} SIGNALING IN CACO2 CELLS.

It is well known that prolonged retention of proteins in the ER can lead to unfolded protein response (UPR) and subsequently activate signaling pathways. There are three branches of UPR known in mammalian cells, including IRE1 (inositol-requiring enzyme 1), PERK (Protein Kinase Related-like ER kinase), and ATF6 (Activating transcription factor $6 ; \alpha$ and $\beta$ isoforms) $[118,119]$. Among these IRE1-XBP1 pathway has been linked to wound healing and mitigation of DSS-colitis [120-122]. Therefore, we tested whether CTBp induces UPR and IRE1-XBP1 signaling in Caco2 cells. Cells were treated with PBS, $1 \mu \mathrm{M}$ rCTB, or $1 \mu \mathrm{M}$ CTBp for 6 or 24 hours and UPR signaling was analyzed by RT-qPCR. Six hours post treatment, CTBp-treated cells showed a significant upregulation of IRE1 while PBS and $\mathrm{rCTB}$ had no effect (Figure 8A). At 24 hours post treatment, all three sensors of the UPR pathway (ATF6, PERK, IRE1), as well as XBP1, CANX (calnexin, ER chaperone for unfolded proteins), PDIA6 (protein disulfide 
isomerase family 6 , ER foldase and regulator of IRE1 signaling), and $T G F \beta 1$, were upregulated in CTBp-treated cells when compared to PBS and/or rCTB (Figure 8B) [123126]. We co-treated Caco2 cells with PBS, CTBp, and/or $4 \mu 8 \mathrm{C}$, an inhibitor of IRE1mediated XBP1 splicing (and hence inhibits the activation IRE1-XBP1 signaling pathway $[127,128]$, after wounding. The analysis revealed that $4 \mu 8 \mathrm{C}$ treatment completely blocked CTBp's wound healing effects; whereas $1 \mu \mathrm{M}$ CTBp treatment significantly enhanced wound closure, $\mathrm{CTBp}+4 \mu 8 \mathrm{C}$ and $4 \mu 8 \mathrm{C}$ treated groups showed no effect (Figure 8B). Furthermore, as shown in Figure 8C, CTBp treatment significantly increased TGF $\beta 1$ and TGF $\beta 2$ levels when compared to PBS, CTBp $+4 \mu 8 \mathrm{C}$ or $4 \mu 8 \mathrm{C}$ treatment. These results indicate that CTBp increases TGF $\beta 1$ and TGF $\beta 2$ levels via the IRE1-XBP1 signaling pathway, which leads to enhanced wound closure in Caco2 cells. 


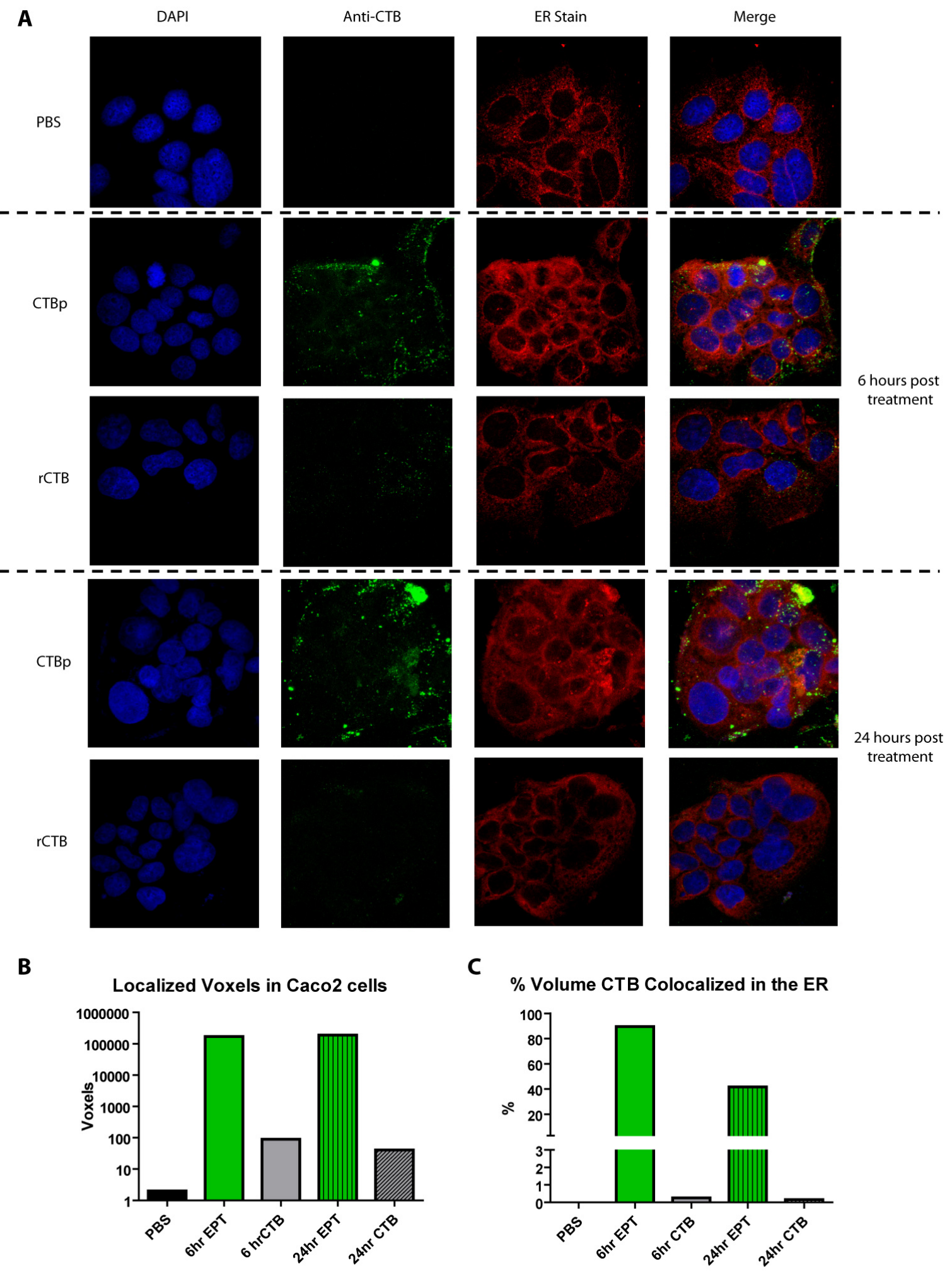

Figure 7. Immunofluorescence analysis of CTBp or rCTB intracellular localization within the ER. Caco2 Cells were treated with $1 \mu \mathrm{M}$ PBS, rCTB, or CTBp for 6 or 24 
hours. Cells were fixed/permeabilized and stained with anti-CTB mAb detected by Alexa FluorTM 488 (green), ER-selective red dye (red), and DAPI (blue). Slides were analyzed by wide-field fluorescence confocal microscope (60x magnification, Z-stacked images). Localization of $\mathrm{rCTB}$ or CTBp within the Caco2 cells or co-localization within the ER statistical analysis was performed using Imaris software (Bitplane), values were calculated in voxels.

\section{A}

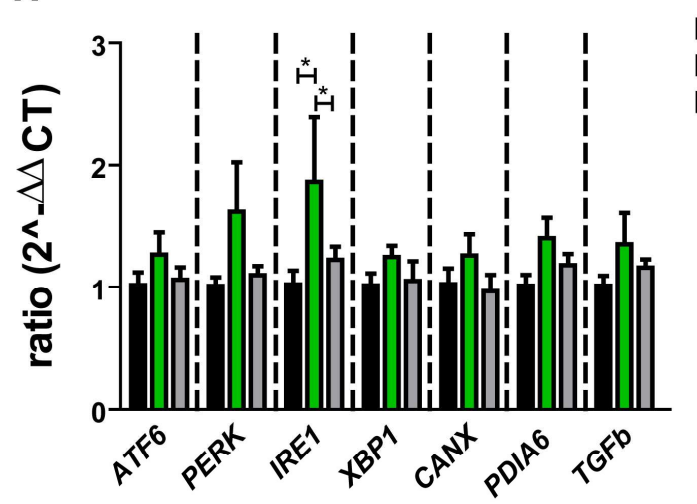

B

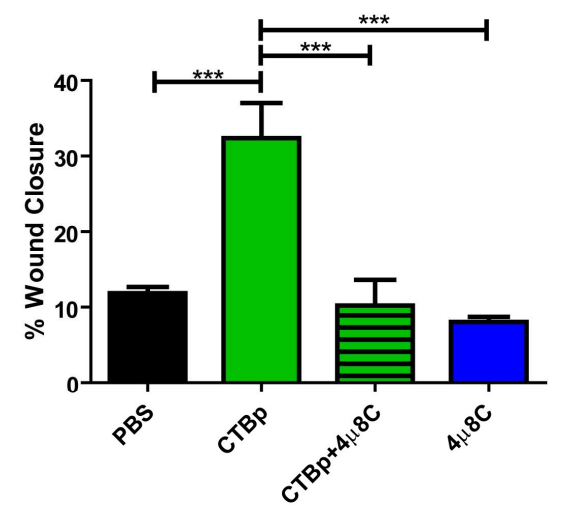

C

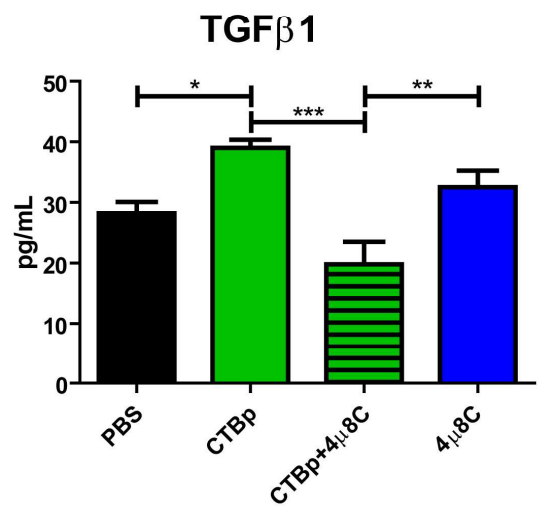

24 hours
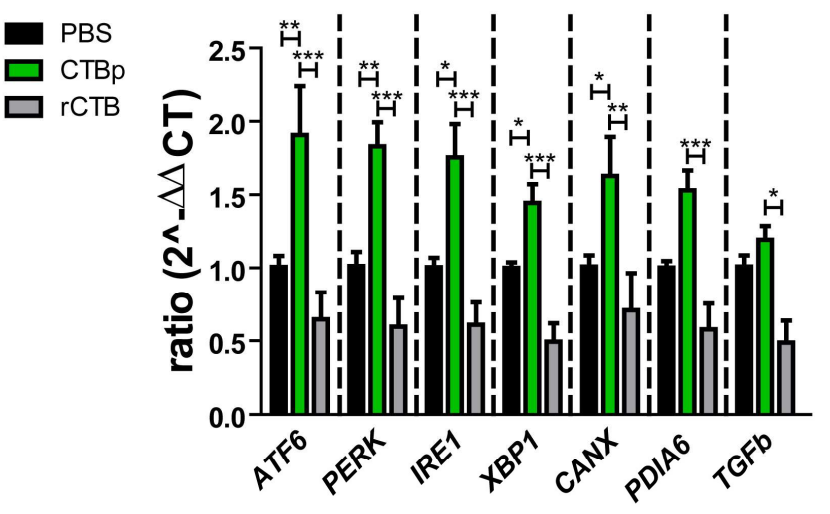

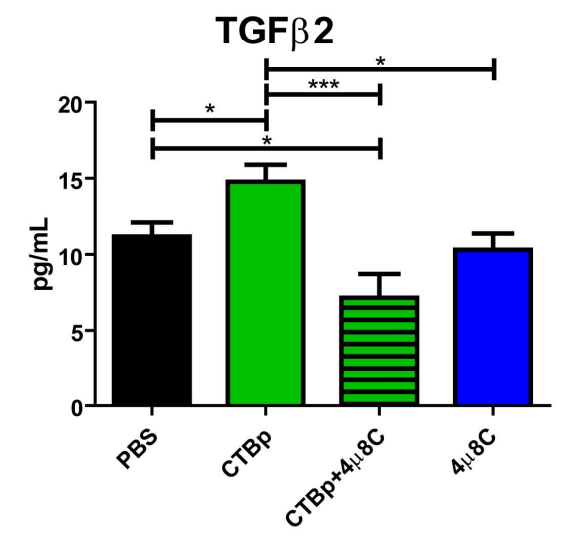


Figure 8. The affects of the UPR on CTBp's wound healing activity. CTBp induces UPR signaling and its epithelial wound healing activity is mediated through IRE1-XBP1 signaling. Caco2 cells were grown to confluence and scratched with a pipette tip. Cells were then incubated with PBS, rCTB, CTBp, and/or 4 $\mu 8 \mathrm{C} .4 \mathrm{x}$ magnification images were acquired to calculate in vitro wound closure over $24 \mathrm{~h}$. Mean percentage closure was determined by Image J software. (a) RT-qPCR analysis of UPR gene expression in Caco2 cells $6 \mathrm{~h}$ or $24 \mathrm{~h}$ after treatment. One-way ANOVA with Bonferroni’s multiple comparison tests was used to compare all pairs of groups between dotting lines. Mean \pm s.e.m. is shown for each group $(\mathrm{N}=4)$. (b) Analysis of in vitro wound closure after $24 \mathrm{~h}$ by wound area measurement. (c) TGF $\beta$ concentrations in Caco 2 cell supernatants from wound healing assay. Mean \pm s.e.m. is shown for each group $(\mathrm{N}=4)$. A one-way ANOVA with Bonferroni's multiple comparison tests was used to compare all pairs of groups $(\mathrm{b}, \mathrm{c})$. Significantly different pairs are highlighted with asterisks $(* \mathrm{P}<0.05, * * \mathrm{P}<$ 0.01 and $* * * \mathrm{P}<0.001)$.

\subsection{CTBP INDUCES A WOUND HEALING RESPONSE IN A HUMAN ULCERATIVE} COLITIS PATIENT COLON TISSUE.

We next explored if the in vitro and in vivo mucosal healing activity of CTBp could translate into a therapeutic effect in human tissue ex vivo. A $3 \times 6 \mathrm{~cm}$ piece of sigmoid colon tissue was received from a 57 year old male UC patient after total colectomy. The tissue was sectioned, cultured, and treated with PBS, CTBp, or rCTB for 24 hours and then UPR, TGF $\beta$, and wound healing signaling was analyzed by RT-qPCR. Consistent with the 6 hour time point in Caco2 cell, the UPR signaling analysis 24 hours post- 
treatment revealed CTBp-treated tissues had a significant upregulation of IREI and TGF $\beta$ while PBS and rCTB had no effect (Figure 9A). A wound healing pathway-focused RTqPCR analysis showed that CTBp significantly enhanced 21 out of 84 wound healing associated genes analyzed, while rCTB significantly enhanced only 1 gene (Figure 9C). No significant effect was observed with PBS treatment. Of the 21 genes significantly increased by CTBp, several noteworthy upregulated genes include $C D H 1, C T G F$, and TGFB1 which are all associated with epithelial wound healing, while both CTBp and rCTB upregulated MAPK1 (Figure 9B). We also performed a TGF $\beta$ signaling pathwayfocused RT-qPCR analysis and found that CTBp treatment enhanced 7 TGF $\beta$ signalingassociated genes, while rCTB had no significant effect in any of the 84 genes analyzed. Congruent with the RT-qPCR results, histopathological analysis showed that CTBptreated tissues $(\mathrm{n}=3$ ) showed early stage crypt formations and relatively low neutrophil infiltration in the mucosa, while PBS- and rCTB-treated tissue did not have such distinct histological features (Figure 10). Since CTBp-treated tissues were cut adjacent from PBS or rCTB-treated ones, these observations likely reflect the effects of treatment. Taken together, these results strongly suggest CTBp's wound healing activity is not limited to single-cell in vitro and mouse in vivo experimental models of inflammation and injury. Thus, highlighting CTBp's therapeutic potential for the treatment of inflammatory diseases of the mucosa, such as UC. 
A

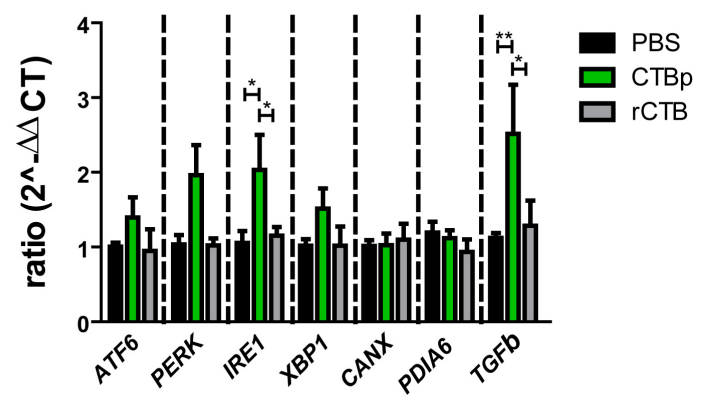

B
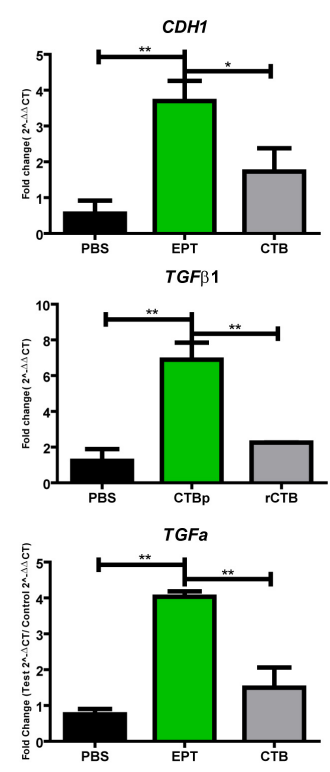

LL-1b

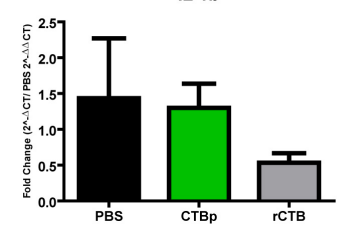

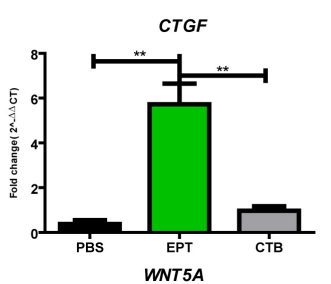
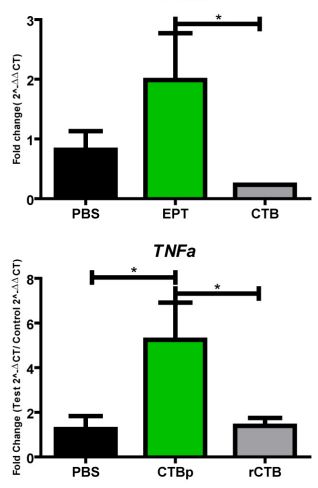

IL-6

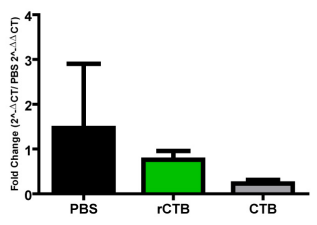

C
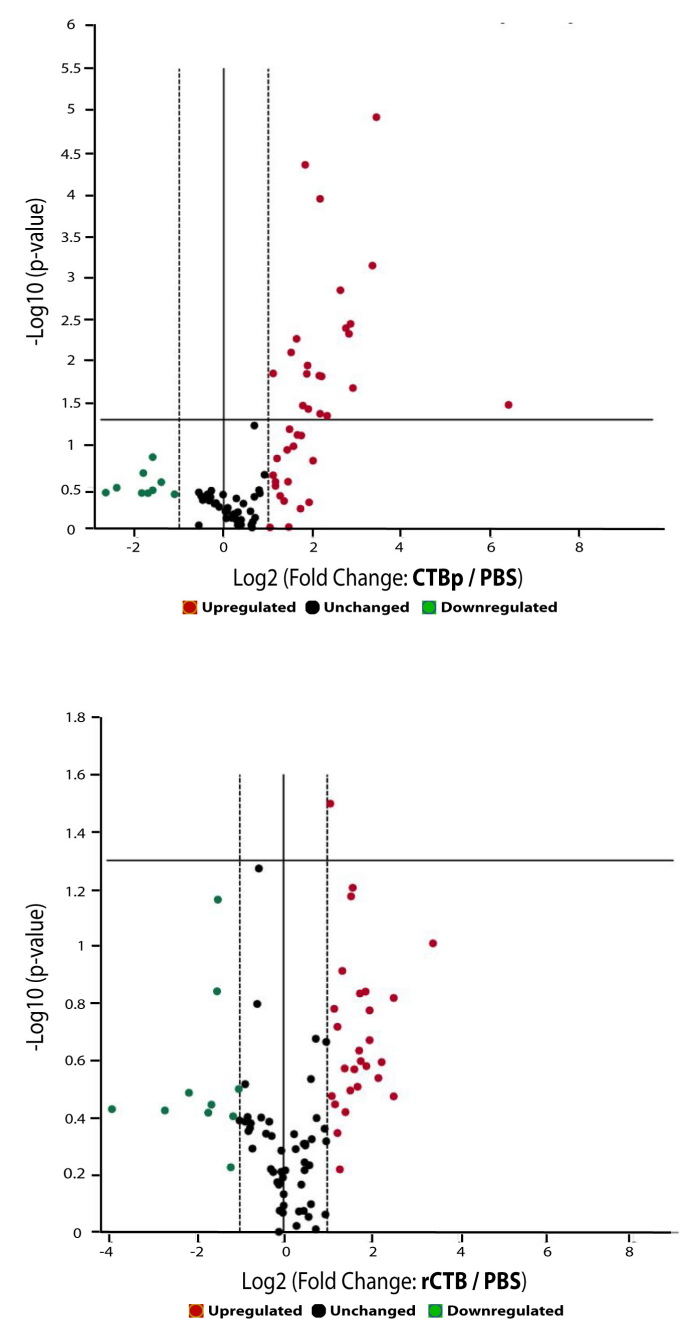

Figure 9. Human UC patient colectomy tissue RT-qPCR analysis. CTBp induces

IRE1, TGF $\beta$, and wound healing signaling in human colon colectomy tissue. Colon tissue obtained from a 57 year old male UC patient who underwent colectomy. The colectomy tissue was divided into nine adjacent sections and cultured with PBS, CTBp, or rCTB for 24 hours. (a) RT-qPCR analysis of UPR gene expression $24 \mathrm{~h}$ after treatment. One-way ANOVA with Bonferroni's multiple comparison tests was used to compare all pairs of groups between dotting lines. Mean \pm s.e.m. is shown for each group $(\mathrm{N}=3)$. (b) 
Representative upregulated genes from wound healing pathway-focused qRT-PCR analysis of gene expression in human UC patient colectomy tissue. Mean \pm s.e.m. is shown for each group $(\mathrm{N}=3)$. A one-way ANOVA with Bonferroni's multiple comparison tests was used to compare all pairs of groups. (c) Wound healing pathwayfocused qRT-PCR analysis of gene expression in human UC patient colectomy tissue. 21 out of 84 genes analyzed were significantly $(\mathrm{P}<0.05)$ upregulated. The graph shows $\mathrm{P}$ value vs. fold-change. Dots represent 2-fold upregulation (red), 2-fold down-regulation (green), or $<2$-foldchange (black). Values were calculated by the data analysis web portal at http://www.qiagen.com/geneglobe $(\mathrm{N}=3)$. 


\section{DISCUSSION}

In this thesis, I aimed to delineate the mechanism by which CTBp's C-terminal KDEL sequence contributes to colonic epithelial wound healing and whether this effect is unique to the plant-made variant. Although CTBp was shown to have similar GM1-ganglioside affinity, conformational stability, and oral immunogenicity to those of rCTB [62], the plant-made protein's C-terminal ER retention signal sequence KDEL, added to improve the protein's production in planta, could theoretically alter the protein's fate upon entering cells [129]. The KDELR is highly conserved among eukaryotic organisms. Once bound to KDEL-containing proteins, the receptor can mediate retrograde transport or harbor proteins in the ER $[25,27,102]$. Moreover, retention of proteins in the ER by the KDELR can lead to UPR and subsequent TGF $\beta$ activation in skin fibroblasts, cervical and lung epithelial cells and shown here in colon epithelial cells [130-134]. Consequently, it is deemed reasonable that the ER retention signal sequence rendered CTB with the new function of mucosal wound healing in Caco2 cells and DSS-induced colitis models, while rCTB showed no noticeable effects in these models. 

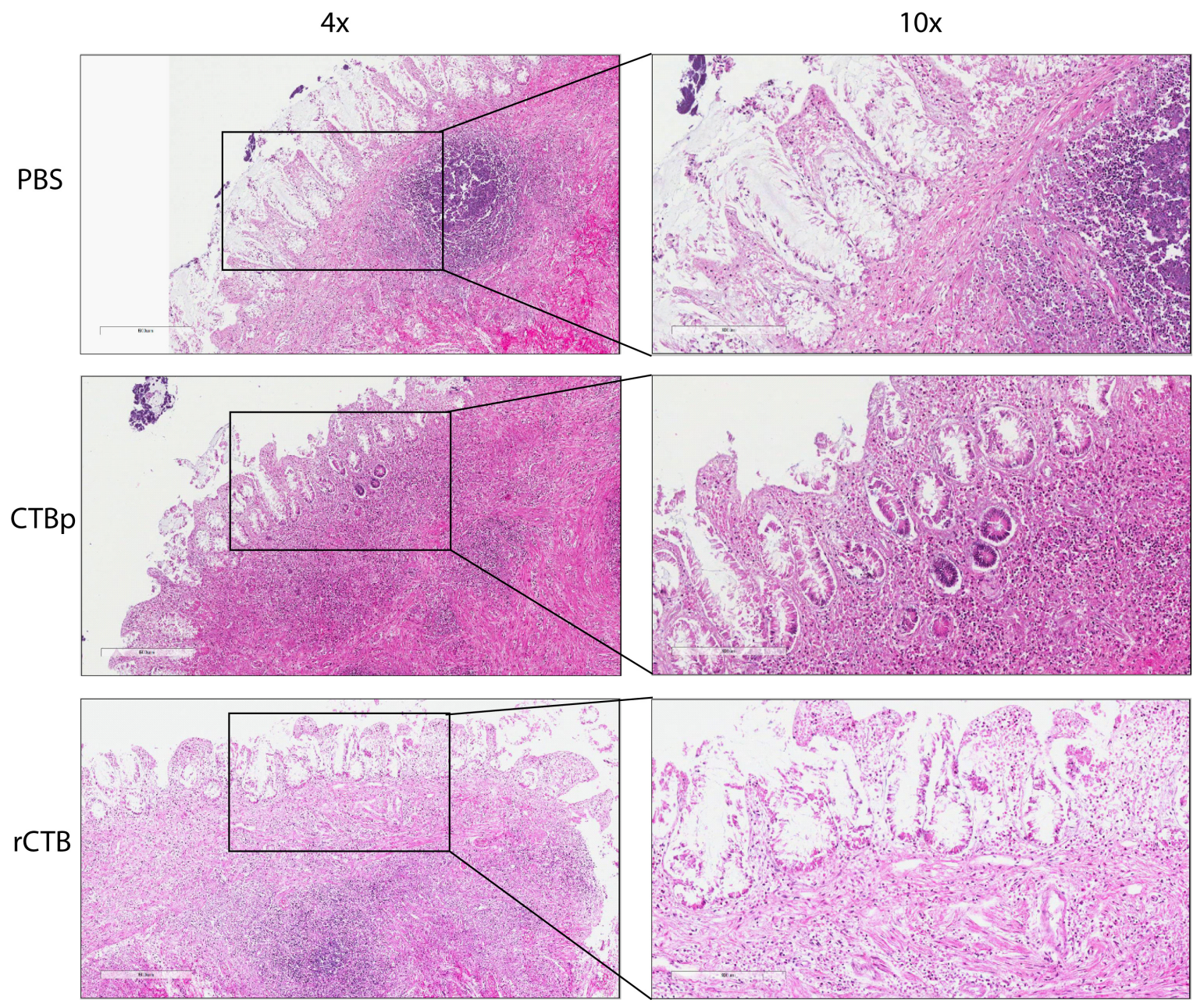

Figure 10. Human UC patient colectomy tissue H\&E stain. Sigmoid colon tissue obtained from a 57 year old male UC patient who underwent colectomy. The colectomy tissue was divided into nine adjacent sections and cultured with PBS, CTBp, or rCTB for 24 hours. Representative 4x (left) and 10x (right) photomicrographs of H\&E stained sigmoid colon tissues from each group.

In the mouse DSS acute colitis model, CTBp oral administration significantly enhanced recovery from colitis as demonstrated in the histopathological, immunohistochemical and gene expression analyses, in contrast to rCTB (Figures 2 and 
3). Boirivant et al. has previously shown that oral administration of $\mathrm{rCTB}$ can resolve TNBS-colitis (a mouse model of Crohn's disease), which was attributed to Th1 cell inhibition $[43,50]$. In contrast, here we have shown that CTBp, but not $\mathrm{CCTB}$, induces epithelial restitution, leading to resolution of epithelial injury and inflammation. Although a direct comparison cannot be made due to two different animal models, the discrepancy in rCTB's efficacies could be in part explained by the different dose amounts and timings employed in those two studies; whereas Boirivant et al. administered 4 daily doses of $100 \mu \mathrm{g}$ rCTB immediately after the administration of TNBS [43, 50], we dosed one $3 \mu \mathrm{g}$ dose of CTBp or $\mathrm{rCTB}$ at the end of DSS exposure. This points to the possibility that the low dose of $\mathrm{rCTB}$ was not sufficient to show a therapeutic effect in the DSS model. Conversely, whether CTBp at high dose levels exhibits T cell-inhibitory effects like rCTB remains to be determined.

In DSS-induced colitis model, the epithelium receives a barrage of mucosal insults, both physical and chemical that result in the loss of the epithelial barrier and damage to the mucosa [68]. Thus, the initial step in injury repair occurs through a rapid migration response of the epithelial sheet (termed restitution) [95, 96]. The process occurs independently of proliferation and results in depolarization of intestinal epithelial cells surrounding the wounded area [96]. This depolarization leads to an epithelial-tomesenchymal transition (EMT) where cells adopt a migratory phenotype induced by increased TGF $\beta$ levels $[97,98]$. Previously, we showed that CTBp induces multiple TGF $\beta$-dependent EMT pathways after treating mice with CTBp [135]. One of the most notable findings in the present DSS study is that the histological and gene expression analyses revealed evidence of epithelial recovery in CTBp-treated groups. The fact that 
the TGF $\beta$ expression level in the CTBp-dosed animals was not significantly high at the time of sacrifice suggests that the cytokine had likely passed its peak expression point. In fact, we observed a significant upregulation of Serpine1, an inhibitor of TGF $\beta$, in the CTBp-dosed group (Figure 2). Additionally, we detected upregulated $C d h 1$ gene in CTBp-treated mice, which is indicative of a late-phase wound healing involving epithelial proliferation and maturation $[109,110,112,136,137]$. E-cadherin expression is inversely correlated with TGF $\beta$ levels due to TGF $\beta$-induced class switching of Ecadherin to N-cadherin which depolarizes cells and allows them to become of migratory phenotype $[98,137,138]$. Thus, the elevated $C d h 1$ levels and strong E-cadherin positive epithelial cell staining that lined the mucosa of CTBp-treated mice indicate the repolarization of the epithelial cells, increased tightening of mucosal barrier and improved mucosal barrier integrity, which are critical steps during restitution [137]. In addition to EMT, TGF $\beta 1$ stimulates and increases expression of WNT5a [136]. WNT5a has been shown to induce new crypt formation and re-establish epithelial homeostasis after injury [136]. The H\&E-stained tissue sections clearly revealed the regeneration and formation of new crypts in the CTBp-dosed group, corroborating the function of upregulated $W n t 5 a$ expression in the colon mucosa. Taken together, these data strongly support the notion that oral administration of CTBp can facilitate colon epithelial restitution and wound healing, at least in the conditions tested in the acute DSS colitis model.

Although CTBp induced significantly higher levels of TGF $\beta 1$ and TGF $\beta 2$ and subsequently facilitated wound closure in Caco 2 cells, rCTB did not show such effects (Figure 4). Three lines of evidence support that these contrasting findings are attributable 
to the artificial KDEL sequence on the C-terminus of CTBp. First, CTBp's efficacy has no link to the plant production platform, as E. coli-produced CTBp exhibited the same effects as the plant-made (Figure 6). Second, a variant of CTBp that lacks the terminal leucine residue (CTB-KDE) failed to induce wound healing. Third, CTBp colocalized and remained longer within the ER of epithelial cells, which is likely due to the KDELtagged protein's ability to interact with the KDELR. Combined with our previous data showing that GM1 binding is essential for CTBp's wound healing effect in Caco2 cells [23], these data strongly suggest that the C-terminal KDEL sequence rendered CTBp with a unique new wound healing activity in the colon epithelial cells.

Even though we determined that the KDEL sequence and the activation of IRE1 signaling are essential for CTBp's efficacy, how the protein activates the IRE1-XBP1 pathway and subsequently induces TGF $\beta$ signaling is yet to be disclosed. Previous studies investigating the intracellular trafficking of CT and $\mathrm{rCTB}$ have shown that CTB's retrograde transportation is triggered upon binding to cell-surface GM1-ganglioside, which allows the proteins to reach deep endomembrane compartments and the ER [27, 139]. As shown in Figure 7A both $\mathrm{rCTB}$ and CTBp were found in the ER, however, the latter was more consistently retained and colocalized within the ER, likely due to its capacity to interact with the KDEL receptor. Aberrant accumulation of proteins, such as CTBp, and misfolding of proteins in the ER can to induce UPR by displacing B cell immunoglobulin protein (BiP) from three main ER transmembrane sensors, IRE1, PERK, and ATF6 [118, 140, 141]. IRE1 represents the most evolutionarily conserved branch of the UPR that is made up of two isoforms, IRE1 $\alpha$ and IRE1 $\beta$, of which IRE1 $\beta$ is unique to the epithelium of the digestive and respiratory tract[142]. Additionally, IRE1-XBP1 
signaling has been linked to TGF $\beta$ activation, wound healing, colon epithelial cell prosurvival signaling, and protection from DSS-induced colitis, as mentioned previously $[120,122,132,133,143]$. In this regard, CTBp significantly increased IRE1 $\alpha$ expression 6 hours after treatment and all 3 arms of UPR sensors (ATF6, PERK, and IREI), as well as the IRE1 signal transducer XBP1, 24 hours after treatment (Figure 8). Furthermore, inhibition of IRE1 signaling by the chemical inhibitor $4 \mu 8 \mathrm{C}$ completely blocked the wound healing activity of CTBp as well as CTBp-mediated TGF $\beta 1$ and TGF $\beta 2$ induction (Figure 8) indicating that CTBp's wound healing activity is mediated through IRE1 signal transduction. Of note, UPR activation is closely linked to ER stress and apoptoptotic pathways [142]. However, we did not observe any cytotoxic response to CTBp up to $10 \mu \mathrm{M}(0.61 \mathrm{mg} / \mathrm{mL})$ in Caco2 cells (Figure 5), suggesting that the protein did not overstimulate UPR beyond the threshold for a cell death response. It is possible that the amount of cell-surface GM1 ganglioside was a limiting factor, whereby the receptor became saturated before the concentration of CTBp reached a point that overload the ER. Further investigation is necessary to understand CTBp's impact on epithelial cell signaling toward TGF $\beta$ expression and EMT, as well as ER stress and survival.

Chronic DSS-colitis is pathologically similar to ulcerative colitis due to is toxicity to colonic epithelial cells, which results in immune responses that alter mucosal barrier function and compromise the colonic epithelium [68]. However, the acute DSS model employed here may not translate well to human IBD. To address this limitation, I have employed an explant culture model using UC patient colectomy tissue to test the mucosal healing potential of CTBp. Although a larger number of UC colon tissues need to be 
tested before a firm conclusion can be justified, the 57 year male patient's specimen showed a remarkable response to CTBp treatment, in contrast to PBS or rCTB. Consistent with the findings in the DSS model, CTBp significantly activated wound healing and TGF $\beta$ signaling pathways, including $C D H 1$, within 24 hours. Additionally, new crypt formations were observed in CTBp-treated tissues (Figure 10). Thus, these results strongly support the premise that CTBp could induce mucosal healing in UC patients. As there is no cure available for $\mathrm{UC}$, mucosal healing is currently regarded as the standard treatment goal in UC therapy [82-87]. Current therapeutic options can achieve mucosal healing in only $\sim 50 \%$ of patients and their direct effect on epithelial repair remains elusive. $[88,89,144]$. Thus, the results presented herein provide implications for the unique therapeutic potential of CTBp that may address a significant unmet need in UC treatment. 


\section{CONCLUSIONS-CHALLENGES FOR THE USE OF CTBP AS AN IMMUNOMODULATORY DRUG}

As discussed above, development of new drug candidates for mucosal healing represent a significant unmet need in UC management. However, currently there is no mucosal wound repair product indicated for UC available or in clinical trials (ClinicalTrials.gov, as of April 2, 2018). Based on the above promising data, we hypothesize that CTBp can be developed as a novel oral biotherapeutic facilitating mucosal healing in UC. Although CTB has been administered in humans in the form of oral cholera vaccines over the past two decades, its development as an immunomodulatory drug will need to address unique issues associated with therapeutic use besides additional testing of safety and efficacy in specific disease indications. CTB can induce potent mucosal and systemic antibody response upon mucosal administration in humans [4, 62]. One critical concern is whether this strong mucosal immunogenicity alters the therapeutic effect of CTBp. The production of anti-drug antibodies (ADA) to IBD therapeutics has strongly been linked to reduced clinical efficacy [145]. ADA can block the binding of therapeutics to its target molecule, as well as, increase the clearance rate, affecting the protein's pharmacokinetics. Furthermore, ADA have been associated with increased frequency of clinical adverse effects [145-148]. Conversely, antibody induction can play an important role in mitigation mucosal inflammation, as demonstration IgA-dependent reduction of experimental asthma described in section 1-2-1 [48]. The aforementioned small-scale 
clinical trial of $\mathrm{rCTB}$ in $\mathrm{CD}$ patients showed a modest efficacy up to 10 weeks after repeated CTB administrations over 2 weeks [51]. Although not reported, the treatment regimen must have elicited high levels of anti-CTB antibodies in the gut and blood circulation. Unfortunately, to date there has been no report on a follow-up study investigating the immunogenicity and long-term efficacy following repeated $\mathrm{rCTB}$ dosing in CD patients. Thus, investigation of the relationship between CTB's immunogenicity and immunotherapeutic efficacy represents a high-priority area for future research.

TGF $\beta$ seems to be a major denominator of CTB-induced immunomodulatory activities. TGF $\beta$ is a pleiotropic cytokine playing critical roles in cell differentiation and proliferation, as well as dynamic biological processes in wound healing and immune responses $[100,149,150]$. The cytokine is also involved in various pathological conditions. For example, elevated TGF $\beta$ levels have been correlated to the development of fibrosis following injury to the skin [151]. TGF $\beta$ mediates epithelial-to-mesenchymal transition (EMT) [152], and reduction of TGF $\beta 1$ levels in a mouse model of pulmonary fibrosis blunted fibrosis [153]. TGF $\beta$ signaling also has important implications in cancer. Although the cytokine functions as a suppressor of tumorigenesis at an early stage of tumor development, its expression is correlated with tumor progression and poor prognosis at late stages $[100,154]$. Collectively, the double-edged sword nature of TGF $\beta$ points to the importance of careful investigation of possible consequences upon longterm CTB dosing for the treatment of chronic inflammatory diseases. As mentioned in the Introduction section, CTBp treatment significantly mitigated gut inflammation and 
reduced tumor development in a model of CAC [23], providing a basis for further investigations of long-term therapeutic use of CTB for the treatment of IBD.

In conclusion, the data herein reveal that CTBp exhibits unique colon mucosal would healing effects that are mediated by its colocalization to the ER and subsequent activation of IRE1-XBP1 signaling in colon epithelial cells. The studies presented herein strongly suggest CTBp's potential as an effective mucosal healing agent with the potential to replace or supplement currently available therapies for the treatment of inflammatory disorders of the mucosa, such as anti-TNF $\alpha$ biologics used in IBD patients who are refractory to conventional medications. As anti-TNF $\alpha$ agents are administered systemically, these agents have limited efficacy for the induction of mucosal healing [ 88 , 89] and/or pose severe adverse reactions [155-157]. In contrast, CTBp might cause few, if any, adverse effects as a topical agent with little systemic absorption, and can directly heal lesions/ulcers and blunt inflammation. Therefore, to aid in developing CTBp-based therapeutic strategies against UC, further research that delineates the detailed mechanisms by which CTBp induces mucosal healing is warranted. Careful investigation of the role of the ER in CTBp's TGF $\beta$ activation in colon epithelial cells may shed light on the mechanistic link to epithelial restitution, facilitating the development of a new topical agent for the treatment of inflammatory diseases of the mucosa. 


\begin{tabular}{|l|l|l|l|l|l|}
\hline $\begin{array}{l}\text { Protein } \\
\text { Name }\end{array}$ & Abrivation & $\begin{array}{l}\text { C-terminal } \\
\text { KDEL } \\
\text { sequence }\end{array}$ & $\begin{array}{l}\text { Production } \\
\text { System }\end{array}$ & $\begin{array}{l}\text { Cholera Toxin } \\
\text { A-subunit } \\
\text { contamination }\end{array}$ & Purification \\
\hline $\begin{array}{l}\text { Recombinant } \\
\text { CTB }\end{array}$ & rCTB & No & E. coli & No & $\begin{array}{l}\text { Chromatography; } \\
>95 \%\end{array}$ \\
\hline $\begin{array}{l}\text { Non- } \\
\text { recombinant } \\
\text { CTB }\end{array}$ & nrCTB & No & E. coli & Yes & N/A \\
\hline $\begin{array}{l}\text { Plant-made } \\
\text { CTB }\end{array}$ & CTBp & Yes & $\begin{array}{l}\text { Nicotiana } \\
\text { benthamiana }\end{array}$ & No & $\begin{array}{l}\text { Chromatography; } \\
>95 \%\end{array}$ \\
\hline $\begin{array}{l}\text { Recombinant } \\
\text { CTB-KDE }\end{array}$ & CTB-KDE & $\begin{array}{l}\text { KDEL } \\
\text { sequence is } \\
\text { lacking Leu } \\
\text { residue }\end{array}$ & E. coli & No & $\begin{array}{l}\text { Chromatography; } \\
>95 \%\end{array}$ \\
\hline $\begin{array}{l}\text { E. coli- } \\
\text { produced } \\
\text { CTBp }\end{array}$ & eCTBp & Yes & E. coli & No & $\begin{array}{l}\text { Chromatography; } \\
>95 \%\end{array}$ \\
\hline
\end{tabular}

Table 1. CTB variants 


\section{REFERENCES}

1. Sanchez, J. and J. Holmgren, Cholera toxin structure, gene regulation and pathophysiological and immunological aspects. Cell Mol Life Sci, 2008. 65(9): p. 1347-60.

2. Finkelstein, R.A. and J.J. LoSpalluto, Pathogenesis of experimental cholera. Preparation and isolation of choleragen and choleragenoid. J Exp Med, 1969. 130(1): p. 185-202.

3. Lonnroth, I. and J. Holmgren, Subunit structure of cholera toxin. J Gen Microbiol, 1973. 76(2): p. 417-27.

4. Baldauf, K.J., et al., Cholera toxin B: one subunit with many pharmaceutical applications. Toxins (Basel), 2015. 7(3): p. 974-96.

5. Cholera vaccines: WHO position paper. Wkly Epidemiol Rec, 2010. 85(13): p. 117-28.

6. Bergquist, $C$., et al., Intranasal vaccination of humans with recombinant cholera toxin $B$ subunit induces systemic and local antibody responses in the upper respiratory tract and the vagina. Infect Immun, 1997. 65(7): p. 2676-84.

7. Jertborn, M., et al., Local and systemic immune responses to rectal administration of recombinant cholera toxin B subunit in humans. Infect Immun, 2001. 69(6): p. 4125-8.

8. Kozlowski, P.A., et al., Comparison of the oral, rectal, and vaginal immunization routes for induction of antibodies in rectal and genital tract secretions of women. Infect Immun, 1997. 65(4): p. 1387-94.

9. Cuatrecasas, P., Interaction of Vibrio cholerae enterotoxin with cell membranes. Biochemistry, 1973. 12(18): p. 3547-58.

10. Kuziemko, G.M., M. Stroh, and R.C. Stevens, Cholera toxin binding affinity and specificity for gangliosides determined by surface plasmon resonance. Biochemistry, 1996. 35(20): p. 6375-84.

11. MacKenzie, C.R., et al., Quantitative analysis of bacterial toxin affinity and specificity for glycolipid receptors by surface plasmon resonance. J Biol Chem, 1997. 272(9): p. 5533-8.

12. Dawson, R.M., Characterization of the binding of cholera toxin to ganglioside GM1 immobilized onto microtitre plates. J Appl Toxicol, 2005. 25(1): p. 30-8.

13. George-Chandy, A., et al., Cholera toxin B subunit as a carrier molecule promotes antigen presentation and increases $C D 40$ and $C D 86$ expression on antigen-presenting cells. Infect Immun, 2001. 69(9): p. 5716-25.

14. Hamorsky, K.T., et al., Rapid and scalable plant-based production of a cholera toxin $B$ subunit variant to aid in mass vaccination against cholera outbreaks. PLoS Negl Trop Dis, 2013. 7(3): p. e2046.

15. Hamorsky, K.T., et al., N-glycosylation of cholera toxin B subunit in Nicotiana benthamiana: impacts on host stress response, production yield and vaccine potential. Sci Rep, 2015. 5: p. 8003.

16. Matoba, N., N-Glycosylation of Cholera Toxin B Subunit: Serendipity for Novel PlantMade Vaccines? Front Plant Sci, 2015. 6: p. 1132.

17. Moore, L., K. Hamorsky, and N. Matoba, Production of Recombinant Cholera Toxin B Subunit in Nicotiana benthamiana Using GENEWARE(R) Tobacco Mosaic Virus Vector. Methods Mol Biol, 2016. 1385: p. 129-37.

18. Sun, J.B., et al., Treatment of experimental autoimmune encephalomyelitis by feeding myelin basic protein conjugated to cholera toxin B subunit. Proc Natl Acad Sci U S A, 1996. 93(14): p. 7196-201. 
19. Ploix, C., et al., Oral administration of cholera toxin B-insulin conjugates protects NOD mice from autoimmune diabetes by inducing CD4+ regulatory T-cells. Diabetes, 1999. 48(11): p. 2150-6.

20. Tarkowski, A., et al., Treatment of experimental autoimmune arthritis by nasal administration of a type II collagen-cholera toxoid conjugate vaccine. Arthritis Rheum, 1999. 42(8): p. 1628-34.

21. Rask, C., et al., Prolonged oral treatment with low doses of allergen conjugated to cholera toxin B subunit suppresses immunoglobulin E antibody responses in sensitized mice. Clin Exp Allergy, 2000. 30(7): p. 1024-32.

22. Stanford, M., et al., Oral tolerization with peptide 336-351 linked to cholera toxin $B$ subunit in preventing relapses of uveitis in Behcet's disease. Clin Exp Immunol, 2004. 137(1): p. 201-8.

23. Baldauf, K.J., et al., Oral administration of a recombinant cholera toxin B subunit promotes mucosal healing in the colon. Mucosal Immunol, 2017. 10(4): p. 887-900.

24. Wernick, N.L., et al., Cholera toxin: an intracellular journey into the cytosol by way of the endoplasmic reticulum. Toxins (Basel), 2010. 2(3): p. 310-25.

25. Chinnapen, D.J., et al., Rafting with cholera toxin: endocytosis and trafficking from plasma membrane to ER. FEMS Microbiol Lett, 2007. 266(2): p. 129-37.

26. Zhang, R.G., et al., The three-dimensional crystal structure of cholera toxin. J Mol Biol, 1995. 251(4): p. 563-73.

27. Lencer, W.I., et al., Targeting of cholera toxin and Escherichia coli heat labile toxin in polarized epithelia: role of COOH-terminal KDEL. J Cell Biol, 1995. 131(4): p. 951-62.

28. Fujinaga, Y., et al., Gangliosides that associate with lipid rafts mediate transport of cholera and related toxins from the plasma membrane to endoplasmic reticulm. Mol Biol Cell, 2003. 14(12): p. 4783-93.

29. Sanchez, J. and J. Holmgren, Cholera toxin - a foe \& a friend. Indian J Med Res, 2011. 133: p. 153-63.

30. Sun, J.B., J. Holmgren, and C. Czerkinsky, Cholera toxin B subunit: an efficient transmucosal carrier-delivery system for induction of peripheral immunological tolerance. Proc Natl Acad Sci U S A, 1994. 91(23): p. 10795-9.

31. Weiner, H.L., Oral tolerance. Proc Natl Acad Sci U S A, 1994. 91(23): p. 10762-5.

32. Bublin, M., et al., Use of a genetic cholera toxin B subunit/allergen fusion molecule as mucosal delivery system with immunosuppressive activity against Th2 immune responses. Vaccine, 2007. 25(50): p. 8395-404.

33. Ruhlman, T., et al., Expression of cholera toxin B-proinsulin fusion protein in lettuce and tobacco chloroplasts--oral administration protects against development of insulitis in non-obese diabetic mice. Plant Biotechnol J, 2007. 5(4): p. 495-510.

34. Carter, J.E., 3rd, et al., Bacterial and plant enterotoxin B subunit-autoantigen fusion proteins suppress diabetes insulitis. Mol Biotechnol, 2006. 32(1): p. 1-15.

35. Arakawa, T., et al., A plant-based cholera toxin B subunit-insulin fusion protein protects against the development of autoimmune diabetes. Nat Biotechnol, 1998. 16(10): p. 9348.

36. Sun, J.B., et al., Intranasal administration of a Schistosoma mansoni glutathione Stransferase-cholera toxoid conjugate vaccine evokes antiparasitic and antipathological immunity in mice. J Immunol, 1999. 163(2): p. 1045-52.

37. McSorley, S.J., et al., Selective tolerization of Th1-like cells after nasal administration of a cholera toxoid-LACK conjugate. Eur J Immunol, 1998. 28(2): p. 424-32. 
38. Czerkinsky, C., et al., Mucosal immunity and tolerance: relevance to vaccine development. Immunol Rev, 1999. 170: p. 197-222.

39. Phipps, P.A., et al., Prevention of mucosally induced uveitis with a HSP60-derived peptide linked to cholera toxin B subunit. Eur J Immunol, 2003. 33(1): p. 224-32.

40. Sun, J.B., et al., Oral administration of cholera toxin B subunit conjugated to myelin basic protein protects against experimental autoimmune encephalomyelitis by inducing transforming growth factor-beta-secreting cells and suppressing chemokine expression. Int Immunol, 2000. 12(10): p. 1449-57.

41. Bergerot, I., et al., A cholera toxoid-insulin conjugate as an oral vaccine against spontaneous autoimmune diabetes. Proc Natl Acad Sci U S A, 1997. 94(9): p. 4610-4.

42. Sun, J.B., C. Czerkinsky, and J. Holmgren, Mucosally induced immunological tolerance, regulatory $T$ cells and the adjuvant effect by cholera toxin B subunit. Scand J Immunol, 2010. 71(1): p. 1-11.

43. Boirivant, M., et al., Oral administration of recombinant cholera toxin subunit B inhibits IL-12-mediated murine experimental (trinitrobenzene sulfonic acid) colitis. J Immunol, 2001. 166(5): p. 3522-32.

44. Tamura, S., et al., Synergistic action of cholera toxin B subunit (and Escherichia coli heatlabile toxin $B$ subunit) and a trace amount of cholera whole toxin as an adjuvant for nasal influenza vaccine. Vaccine, 1994. 12(5): p. 419-26.

45. Kim, P.H., et al., Cholera toxin and cholera toxin B subunit induce IgA switching through the action of TGF-beta 1. J Immunol, 1998. 160(3): p. 1198-203.

46. Reinholdt J, H.S., IgA and Mucosal Homeostasis. Madame Curie Bioscience Database, 2000-2013.

47. Corthesy, B., Role of secretory IgA in infection and maintenance of homeostasis. Autoimmunity reviews, 2013. 12(6): p. 661-5.

48. Smits, H.H., et al., Cholera toxin B suppresses allergic inflammation through induction of secretory IgA. Mucosal Immunol, 2009. 2(4): p. 331-9.

49. Neurath, M.F., S. Finotto, and L.H. Glimcher, The role of Th1/Th2 polarization in mucosal immunity. Nat Med, 2002. 8(6): p. 567-73.

50. Coccia, E.M., et al., Cholera toxin subunit B inhibits IL-12 and IFN-\{gamma\} production and signaling in experimental colitis and Crohn's disease. Gut, 2005. 54(11): p. 1558-64.

51. Stal, P., et al., Clinical trial: the safety and short-term efficacy of recombinant cholera toxin B subunit in the treatment of active Crohn's disease. Aliment Pharmacol Ther, 2010. 31(3): p. 387-95.

52. Aman, A.T., et al., A mutant cholera toxin B subunit that binds GM1-ganglioside but lacks immunomodulatory or toxic activity. Proc Natl Acad Sci U S A, 2001. 98(15): p. 8536-41.

53. D'Ambrosio, A., et al., Cholera toxin $B$ subunit promotes the induction of regulatory $T$ cells by preventing human dendritic cell maturation. J Leukoc Biol, 2008. 84(3): p. 661-8.

54. Rouquette-Jazdanian, A.K., et al., Cholera toxin B-subunit prevents activation and proliferation of human $C D 4+T$ cells by activation of a neutral sphingomyelinase in lipid rafts. J Immunol, 2005. 175(9): p. 5637-48.

55. Dbaibo, G.S., et al., Retinoblastoma gene product as a downstream target for a ceramide-dependent pathway of growth arrest. Proc Natl Acad Sci U S A, 1995. 92(5): p. 1347-51.

56. Lee, J.Y., Y.A. Hannun, and L.M. Obeid, Ceramide inactivates cellular protein kinase Calpha. J Biol Chem, 1996. 271(22): p. 13169-74. 
57. Lee, J.Y., Y.A. Hannun, and L.M. Obeid, Functional dichotomy of protein kinase C (PKC) in tumor necrosis factor-alpha (TNF-alpha) signal transduction in L929 cells. Translocation and inactivation of PKC by TNF-alpha. J Biol Chem, 2000. 275(38): p. 29290-8.

58. Leoni, G., et al., Wound repair: role of immune-epithelial interactions. Mucosal immunology, 2015. 8(5): p. 959-68.

59. Kurashima, Y. and H. Kiyono, Mucosal Ecological Network of Epithelium and Immune Cells for Gut Homeostasis and Tissue Healing. Annu Rev Immunol, 2017. 35: p. 119-147.

60. Ma, D., et al., Interleukin-10 and nerve growth factor have reciprocal upregulatory effects on intestinal epithelial cells. Am J Physiol Regul Integr Comp Physiol, 2003. 284(5): p. R1323-9.

61. Stordeur, P. and M. Goldman, Interleukin-10 as a regulatory cytokine induced by cellular stress: molecular aspects. Int Rev Immunol, 1998. 16(5-6): p. 501-22.

62. Hamorsky, K.T., et al., Rapid and scalable plant-based production of a cholera toxin $B$ subunit variant to aid in mass vaccination against cholera outbreaks. PLoS neglected tropical diseases, 2013. 7(3): p. e2046.

63. Zhang, L., et al., Anti-inflammatory effect of cholera toxin B subunit in experimental stroke. J Neuroinflammation, 2016. 13(1): p. 147.

64. Aspord, C., et al., alpha4 integrins and L-selectin differently orchestrate T-cell activity during diabetes prevention following oral administration of CTB-insulin. J Autoimmun, 2002. 19(4): p. 223-32.

65. Wynn, T.A. and K.M. Vannella, Macrophages in Tissue Repair, Regeneration, and Fibrosis. Immunity, 2016. 44(3): p. 450-462.

66. Satoh, Y., et al., Cyclosporine regulates intestinal epithelial apoptosis via TGF-betarelated signaling. Am J Physiol Gastrointest Liver Physiol, 2009. 297(3): p. G514-9.

67. Taverna, D., et al., Imaging mass spectrometry for assessing cutaneous wound healing: analysis of pressure ulcers. J Proteome Res, 2015. 14(2): p. 986-96.

68. Kiesler, P., I.J. Fuss, and W. Strober, Experimental Models of Inflammatory Bowel Diseases. Cell Mol Gastroenterol Hepatol, 2015. 1(2): p. 154-170.

69. Perse, M. and A. Cerar, Dextran sodium sulphate colitis mouse model: traps and tricks. J Biomed Biotechnol, 2012. 2012: p. 718617.

70. Clapper, M.L., H.S. Cooper, and W.C. Chang, Dextran sulfate sodium-induced colitisassociated neoplasia: a promising model for the development of chemopreventive interventions. Acta Pharmacol Sin, 2007. 28(9): p. 1450-9.

71. Jiminez, J.A., et al., Animal models to study acute and chronic intestinal inflammation in mammals. Gut Pathog, 2015. 7: p. 29.

72. Chassaing, B., et al., Dextran sulfate sodium (DSS)-induced colitis in mice. Curr Protoc Immunol, 2014. 104: p. Unit 15.25.

73. Yashiro, M., Ulcerative colitis-associated colorectal cancer. World J Gastroenterol, 2014. 20(44): p. 16389-97.

74. Grivennikov, S.I., Inflammation and colorectal cancer: colitis-associated neoplasia. Semin Immunopathol, 2013. 35(2): p. 229-44.

75. Terzic, J., et al., Inflammation and colon cancer. Gastroenterology, 2010. 138(6): p. 2101-2114.e5.

76. Jawad, N., N. Direkze, and S.J. Leedham, Inflammatory bowel disease and colon cancer. Recent Results Cancer Res, 2011. 185: p. 99-115.

77. Ng, S.C., et al., Worldwide incidence and prevalence of inflammatory bowel disease in the 21st century: a systematic review of population-based studies. The Lancet. 390(10114): p. 2769-2778. 
78. Kaser, A., S. Zeissig, and R.S. Blumberg, Inflammatory bowel disease. Annu Rev Immunol, 2010. 28: p. 573-621.

79. Saleh, M. and G. Trinchieri, Innate immune mechanisms of colitis and colitis-associated colorectal cancer. Nat Rev Immunol, 2011.

80. Pagnini, C., et al., "Mucosal healing" in ulcerative colitis: Between clinical evidence and market suggestion. World J Gastrointest Pathophysiol, 2014. 5(2): p. 54-62.

81. Park, S.C. and Y.T. Jeen, Current and emerging biologics for ulcerative colitis. Gut Liver, 2015. 9(1): p. 18-27.

82. lizuka, M. and S. Konno, Wound healing of intestinal epithelial cells. World J Gastroenterol, 2011. 17(17): p. 2161-71.

83. Neurath, M.F., New targets for mucosal healing and therapy in inflammatory bowel diseases. Mucosal Immunol, 2014. 7(1): p. 6-19.

84. Ferrari, L., M.K. Krane, and A. Fichera, Inflammatory bowel disease surgery in the biologic era. World J Gastrointest Surg, 2016. 8(5): p. 363-70.

85. Pineton de Chambrun, G., et al., Clinical implications of mucosal healing for the management of IBD. Nat Rev Gastroenterol Hepatol, 2010. 7(1): p. 15-29.

86. Orlando, A., et al., Clinical implications of mucosal healing in the management of patients with inflammatory bowel disease. Dig Liver Dis, 2013. 45(12): p. 986-91.

87. Boal Carvalho, P. and J. Cotter, Mucosal Healing in Ulcerative Colitis: A Comprehensive Review. Drugs, 2017. 77(2): p. 159-173.

88. Villanacci, V., et al., Histological healing in inflammatory bowel disease: a still unfulfilled promise. World J Gastroenterol, 2013. 19(7): p. 968-78.

89. Vaughn, B.P., S. Shah, and A.S. Cheifetz, The role of mucosal healing in the treatment of patients with inflammatory bowel disease. Curr Treat Options Gastroenterol, 2014.

12(1): p. 103-17.

90. Leoni, G., et al., Wound repair: role of immune-epithelial interactions. Mucosal Immunol, 2015. 8(5): p. 959-68.

91. Walsh, A.J., R.V. Bryant, and S.P. Travis, Current best practice for disease activity assessment in IBD. Nat Rev Gastroenterol Hepatol, 2016. 13(10): p. 567-79.

92. Finnson, K.W., et al., Dynamics of Transforming Growth Factor Beta Signaling in Wound Healing and Scarring. Adv Wound Care (New Rochelle), 2013. 2(5): p. 195-214.

93. Pakyari, M., et al., Critical Role of Transforming Growth Factor Beta in Different Phases of Wound Healing. Adv Wound Care (New Rochelle), 2013. 2(5): p. 215-224.

94. Reinke, J.M. and H. Sorg, Wound repair and regeneration. Eur Surg Res, 2012. 49(1): p. 35-43.

95. Lacy, E.R. and S. Ito, Rapid epithelial restitution of the rat gastric mucosa after ethanol injury. Lab Invest, 1984. 51(5): p. 573-83.

96. Dignass, A.U. and D.K. Podolsky, Cytokine modulation of intestinal epithelial cell restitution: central role of transforming growth factor beta. Gastroenterology, 1993. 105(5): p. 1323-32.

97. Cho, H.J., et al., Snail is required for transforming growth factor-beta-induced epithelialmesenchymal transition by activating PI3 kinase/Akt signal pathway. Biochem Biophys Res Commun, 2007. 353(2): p. 337-43.

98. Leight, J.L., et al., Matrix rigidity regulates a switch between TGF-beta1-induced apoptosis and epithelial-mesenchymal transition. Mol Biol Cell, 2012. 23(5): p. 781-91.

99. Biancheri, P., et al., The role of transforming growth factor (TGF)-beta in modulating the immune response and fibrogenesis in the gut. Cytokine Growth Factor Rev, 2014. 25(1): p. 45-55. 
100. Morikawa, M., R. Derynck, and K. Miyazono, TGF-beta and the TGF-beta Family: Context-Dependent Roles in Cell and Tissue Physiology. Cold Spring Harb Perspect Biol, 2016. 8(5).

101. Boirivant, M., et al., Inhibition of Smad7 with a specific antisense oligonucleotide facilitates TGF-beta1-mediated suppression of colitis. Gastroenterology, 2006. 131(6): p. 1786-98.

102. Denecke, J., R. De Rycke, and J. Botterman, Plant and mammalian sorting signals for protein retention in the endoplasmic reticulum contain a conserved epitope. Embo $\mathrm{j}$, 1992. 11(6): p. 2345-55.

103. Dionne, S., et al., Colonic explant production of IL-1and its receptor antagonist is imbalanced in inflammatory bowel disease (IBD). Clin Exp Immunol, 1998. 112(3): p. 435-42.

104. Randall, K.J., J. Turton, and J.R. Foster, Explant culture of gastrointestinal tissue: a review of methods and applications. Cell Biol Toxicol, 2011. 27(4): p. 267-84.

105. Okayasu, I., et al., A novel method in the induction of reliable experimental acute and chronic ulcerative colitis in mice. Gastroenterology, 1990. 98(3): p. 694-702.

106. Cooper, H.S., et al., Clinicopathologic study of dextran sulfate sodium experimental murine colitis. Lab Invest, 1993. 69(2): p. 238-49.

107. Dame, M.K., et al., Human colonic crypts in culture: segregation of immunochemical markers in normal versus adenoma-derived. Lab Invest, 2014. 94(2): p. 222-34.

108. Zeisberg, M. and E.G. Neilson, Biomarkers for epithelial-mesenchymal transitions. J Clin Invest, 2009. 119(6): p. 1429-37.

109. Luissint, A.C., C.A. Parkos, and A. Nusrat, Inflammation and the Intestinal Barrier: Leukocyte-Epithelial Cell Interactions, Cell Junction Remodeling, and Mucosal Repair. Gastroenterology, 2016. 151(4): p. 616-32.

110. Zhang, D.L., et al., Effect of Wnt signaling pathway on wound healing. Biochem Biophys Res Commun, 2009. 378(2): p. 149-51.

111. Sturm, A. and A.U. Dignass, Epithelial restitution and wound healing in inflammatory bowel disease. World J Gastroenterol, 2008. 14(3): p. 348-53.

112. Park, H.J., et al., Electrical Stimulation Modulates the Expression of Multiple Wound Healing Genes in Primary Human Dermal Fibroblasts. Tissue Eng Part A, 2015. 21(13-14): p. 1982-90.

113. Babickova, J., et al., Sex Differences in Experimentally Induced Colitis in Mice: a Role for Estrogens. Inflammation, 2015. 38(5): p. 1996-2006.

114. Capitani, M. and M. Sallese, The KDEL receptor: new functions for an old protein. FEBS Lett, 2009. 583(23): p. 3863-71.

115. Cabrera, M., et al., The retrieval function of the KDEL receptor requires $P K A$ phosphorylation of its C-terminus. Mol Biol Cell, 2003. 14(10): p. 4114-25.

116. Becker, B., et al., Cargo binding promotes KDEL receptor clustering at the mammalian cell surface. Sci Rep, 2016. 6: p. 28940.

117. Lewis, M.J. and H.R. Pelham, A human homologue of the yeast HDEL receptor. Nature, 1990. 348(6297): p. 162-3.

118. Walter, P. and D. Ron, The unfolded protein response: from stress pathway to homeostatic regulation. Science, 2011. 334(6059): p. 1081-6.

119. Ron, D. and P. Walter, Signal integration in the endoplasmic reticulum unfolded protein response. Nat Rev Mol Cell Biol, 2007. 8(7): p. 519-29.

120. Bertolotti, A., et al., Increased sensitivity to dextran sodium sulfate colitis in IRE1betadeficient mice. J Clin Invest, 2001. 107(5): p. 585-93. 
121. Zhang, H., et al., Colitis Is Effectively Ameliorated by (+/-)-8-Acetonyl-dihydrocoptisine via the XBP1-NF-kappaB Pathway. Front Pharmacol, 2017. 8: p. 619.

122. Wang, J.M., et al., Inositol-Requiring Enzyme 1 Facilitates Diabetic Wound Healing Through Modulating MicroRNAs. Diabetes, 2017. 66(1): p. 177-192.

123. Lamriben, L., et al., N-Glycan-based ER Molecular Chaperone and Protein Quality Control System: The Calnexin Binding Cycle. Traffic, 2016. 17(4): p. 308-26.

124. Eletto, D., et al., Protein disulfide isomerase A6 controls the decay of IRE1alpha signaling via disulfide-dependent association. Mol Cell, 2014. 53(4): p. 562-576.

125. Sepulveda, D., et al., Interactome Screening Identifies the ER Luminal Chaperone Hsp47 as a Regulator of the Unfolded Protein Response Transducer IRE1alpha. Mol Cell, 2018. 69(2): p. 238-252.e7.

126. Groenendyk, J., et al., Interplay between the oxidoreductase PDIA6 and microRNA-322 controls the response to disrupted endoplasmic reticulum calcium homeostasis. Sci Signal, 2014. 7(329): p. ra54.

127. Cross, B.C., et al., The molecular basis for selective inhibition of unconventional mRNA splicing by an IRE1-binding small molecule. Proc Natl Acad Sci U S A, 2012. 109(15): p. E869-78.

128. Zhang, L., et al., IRE1 inhibition perturbs the unfolded protein response in a pancreatic beta-cell line expressing mutant proinsulin, but does not sensitize the cells to apoptosis. BMC Cell Biol, 2014. 15: p. 29.

129. Royal, J.M. and N. Matoba, Therapeutic Potential of Cholera Toxin B Subunit for the Treatment of Inflammatory Diseases of the Mucosa. Toxins (Basel), 2017. 9(12).

130. Yamamoto, K., et al., The KDEL receptor mediates a retrieval mechanism that contributes to quality control at the endoplasmic reticulum. Embo j, 2001. 20(12): p. 3082-91.

131. Yamamoto, K., et al., The KDEL receptor modulates the endoplasmic reticulum stress response through mitogen-activated protein kinase signaling cascades. J Biol Chem, 2003. 278(36): p. 34525-32.

132. Chusri, P., et al., HCV induces transforming growth factor beta1 through activation of endoplasmic reticulum stress and the unfolded protein response. Sci Rep, 2016. 6: p. 22487.

133. Matsuzaki, S., et al., Physiological ER Stress Mediates the Differentiation of Fibroblasts. PLoS One, 2015. 10(4): p. e0123578.

134. Roberson, E.C., et al., Influenza induces endoplasmic reticulum stress, caspase-12dependent apoptosis, and c-Jun N-terminal kinase-mediated transforming growth factor-beta release in lung epithelial cells. Am J Respir Cell Mol Biol, 2012. 46(5): p. 57381.

135. Baldauf, K.J., et al., Oral administration of a recombinant cholera toxin B subunit promotes mucosal healing in the colon. Mucosal Immunol, 2016.

136. Miyoshi, H., et al., Wnt5a potentiates TGF-beta signaling to promote colonic crypt regeneration after tissue injury. Science, 2012. 338(6103): p. 108-13.

137. Hwang, S., et al., E-cadherin is critical for collective sheet migration and is regulated by the chemokine CXCL12 protein during restitution. J Biol Chem, 2012. 287(26): p. 2222740.

138. Araki, K., et al., E/N-cadherin switch mediates cancer progression via TGF-beta-induced epithelial-to-mesenchymal transition in extrahepatic cholangiocarcinoma. Br J Cancer, 2011. 105(12): p. 1885-93.

139. Geiger, R., et al., Investigating endocytic pathways to the endoplasmic reticulum and to the cytosol using SNAP-trap. Traffic, 2013. 14(1): p. 36-46. 
140. Todd, D.J., A.H. Lee, and L.H. Glimcher, The endoplasmic reticulum stress response in immunity and autoimmunity. Nat Rev Immunol, 2008. 8(9): p. 663-74.

141. Schroder, M. and R.J. Kaufman, The mammalian unfolded protein response. Annu Rev Biochem, 2005. 74: p. 739-89.

142. Kaser, A., et al., The unfolded protein response and its role in intestinal homeostasis and inflammation. Exp Cell Res, 2011. 317(19): p. 2772-9.

143. Cao, S.S., B. Song, and R.J. Kaufman, PKR protects colonic epithelium against colitis through the unfolded protein response and prosurvival signaling. Inflamm Bowel Dis, 2012. 18(9): p. 1735-42.

144. Okamoto, R. and M. Watanabe, Role of epithelial cells in the pathogenesis and treatment of inflammatory bowel disease. J Gastroenterol, 2016. 51(1): p. 11-21.

145. Yin, L., et al., Therapeutic outcomes, assessments, risk factors and mitigation efforts of immunogenicity of therapeutic protein products. Cell Immunol, 2015. 295(2): p. 118-26.

146. Swanson, S.J. and J. Bussiere, Immunogenicity assessment in non-clinical studies. Curr Opin Microbiol, 2012. 15(3): p. 337-47.

147. Baert, F., et al., Influence of immunogenicity on the long-term efficacy of infliximab in Crohn's disease. N Engl J Med, 2003. 348(7): p. 601-8.

148. Vultaggio, A., et al., Anti-infliximab IgE and non-IgE antibodies and induction of infusionrelated severe anaphylactic reactions. Allergy, 2010. 65(5): p. 657-61.

149. Biancheri, P., et al., The role of transforming growth factor (TGF)-beta in modulating the immune response and fibrogenesis in the gut. Cytokine \& growth factor reviews, 2014. 25(1): p. 45-55.

150. Travis, M.A. and D. Sheppard, TGF-beta activation and function in immunity. Annual review of immunology, 2014. 32: p. 51-82.

151. Penn, J.W., A.O. Grobbelaar, and K.J. Rolfe, The role of the TGF-beta family in wound healing, burns and scarring: a review. Int J Burns Trauma, 2012. 2(1): p. 18-28.

152. Kim, M.K., et al., The differential expression of TGF-beta1, ILK and wnt signaling inducing epithelial to mesenchymal transition in human renal fibrogenesis: an immunohistochemical study. Int J Clin Exp Pathol, 2013. 6(9): p. 1747-58.

153. Zhang, Y.Q., et al., Resveratrol ameliorates lipopolysaccharide-induced epithelial mesenchymal transition and pulmonary fibrosis through suppression of oxidative stress and transforming growth factor-beta1 signaling. Clin Nutr, 2015. 34(4): p. 752-60.

154. Colak, S. and P. Ten Dijke, Targeting TGF-beta Signaling in Cancer. Trends Cancer, 2017. 3(1): p. 56-71.

155. Hansel, T.T., et al., The safety and side effects of monoclonal antibodies. Nat Rev Drug Discov, 2010. 9(4): p. 325-38.

156. Murdaca, G., et al., Infection risk associated with anti-TNF-alpha agents: a review. Expert Opin Drug Saf, 2015. 14(4): p. 571-82.

157. Saleh, M. and G. Trinchieri, Innate immune mechanisms of colitis and colitis-associated colorectal cancer. Nat Rev Immunol, 2011. 11(1): p. 9-20. 
Joshua Royal

Clinical and Translational Research Building, Lab 626b

505 S. Hancock Street

Louisville, Ky 40202

(270) 315-4205

E-mail: Joshua.royal@louisville.edu

\title{
EDUCATION
}

2009-2013 B.Sc. in Molecular Biology with a minor in Psychology, Western Kentucky University, Ogden College of Science and Engineering, Bowling Green, KY

2016-2018 M.Sc. in Pharmacology and Toxicology, Department of Pharmacology and Toxicology, University of Louisville School of Medicine, Louisville, Ky (Advisor: Nobuyuki Matoba, Ph.D.)

2018-TBD Ph.D. in Pharmacology and Toxicology, Department of Pharmacology and Toxicology, University of Louisville School of Medicine, Louisville, Ky (Advisor: Nobuyuki Matoba, Ph.D.). Expected Graduation Date:

December 2019

\section{ACADEMIC APPOINTMENTS}

\author{
5/2014-2/2017 Research Technician \\ James Graham Brown Cancer Center, University of Louisville \\ School of Medicine, Louisville, KY \\ 2/2017 - present $\quad$ Research Technician II/Research Lab Manager \\ James Graham Brown Cancer Center, University of Louisville \\ School of Medicine, Louisville, KY
}

\section{OTHER POSITIONS AND EMPLOYMENT}


Biopharmaceutical Research Unit, University of Louisville, Louisville, KY

$9 / 2013-4 / 2014$

Research Technician

Owensboro Cancer Research Program, Owensboro Health, Owensboro, KY

\section{PROFESSIONAL MEMBERSHIPS AND ACTIVITIES}

3/2018 - present Member of the American Gastroenterology Association

9/2017 - Present Member of the American Association for the Advancement of Science

6/2013 - Present Member of the National Animal Health Emergency Response Corps

\section{HONORS AND AWARDS}

2014

2014

2016

2016

2017

2018

2018

2018
Research Staff Award (1st Place), Research Louisville 2014, University of Louisville.

Roving Research Award ( ${ }^{\text {nd }}$ Place), James Graham Brown Cancer Center $14^{\text {th }}$ Annual Retreat.

Masters Basic-Science Graduate Student Award (2nd Place), Research Louisville 2016, University of Louisville.

Best Presentation Award (1st Place), Center for Predictive Medicine Retreat 2016.

Masters Basic-Science Graduate Student Award (1st Place), Research Louisville 2017, University of Louisville.

Graduate Merit Scholarship, University of Louisville Graduate School Council.

Basic Science Travel Award, Digestive Disease Week 2018

Certificate of Recognition for Early Career GIs, American Association for the Advancement of Science 


\section{CERTIFICATION, LICENSURE, AND TRAINING}

$\begin{array}{ll}\text { 9/2013-9/2018 } & \text { NIH Guidelines } \\ 6 / 2014-6 / 2019 & \text { Basic Biosafety Training } \\ 6 / 2014 & \text { HIPAA Privacy Training (Non-Research) } \\ 6 / 2014 & \text { HIPAA Security/Information Security } \\ 8 / 2015-8 / 2018 & \text { Laboratory Safety and Hazardous Waste Training } \\ \text { 9/2015-9/2018 } & \text { Hazardous Waste Training } \\ 3 / 2016-3 / 2020 & \text { Human Subjects and HIPAA-Research/Biomedical Research } \\ 3 / 2016-2 / 2020 & \text { Institutional Compliance - U of L General Population } \\ 6 / 2017-6 / 2018 & \text { Bloodborne Pathogens Training } \\ 7 / 2017-7 / 2020 & \text { Occupational Health and Safety Training for Animal Handlers } \\ 4 / 2017-4 / 2018 & \text { Good Laboratory Practice (GLP) Training: for Non-Clinical } \\ & \text { Testing } \\ 4 / 2017-4 / 2018 & \text { GLP Training: Standard Operating Procedure (SOP) Training } \\ 4 / 2017-4 / 2018 & \text { GLP Training: SOP Implementation }\end{array}$

\section{EDUCATIONAL ACTIVITIES}

Lectures in formal courses

$8 / 2016$

9/2016

9/2016
Student Instructor of PHTX 641 Graduate Pharmacology I, Fall 2016 (Drug Invention and the Pharmaceutical Industry), Department of Pharmacology and Toxicology, University of Louisville

Student Instructor of PHTX 641 Graduate Pharmacology I, Fall 2016 (Pharmacogenetics), Department of Pharmacology and Toxicology, University of Louisville

Student Instructor of PHTX 643 Graduate Toxicology I, Fall 2016 (Environmental Estrogen Effects on Ovarian Function), 
9/2016

$9 / 2016$

$10 / 2016$

$11 / 2016$

$11 / 2016$

$12 / 2016$

$1 / 2017$

$1 / 2017$

$2 / 2017$

$2 / 2017$

$2 / 2017$

$3 / 2017$
Student Instructor of PHTX 643 Graduate Toxicology I, Fall 2016 (Nanoparticles, Health and Safety Concerns), Department of Pharmacology and Toxicology, University of Louisville

Student Instructor of PHTX 643 Graduate Toxicology I, Fall 2016 (Toxic Responses of the Liver), Department of Pharmacology and Toxicology, University of Louisville

Student Instructor of PHTX 643 Graduate Toxicology I, Fall 2016 (Toxic Responses of the Vascular System), Department of Pharmacology and Toxicology, University of Louisville

Student Instructor of PHTX 641 Graduate Pharmacology I, Fall 2016 (Hypnotics and Sedatives) Department of Pharmacology and Toxicology, University of Louisville

Student Instructor of PHTX 643 Graduate Toxicology I, Fall 2016 (Molecular and genetic changes in Asbestos-Related Lung Cancer), Department of Pharmacology and Toxicology, University of Louisville

Student Instructor of PHTX 643 Graduate Toxicology I, Fall 2016 (Transcriptomics), Department of Pharmacology and Toxicology, University of Louisville

Student Instructor of PHTX 642 Graduate Pharmacology II, Spring 2017 (Protein Synthesis Inhibitors and Miscellaneous Antibacterial Agents), Department of Pharmacology and Toxicology, University of Louisville

Student Instructor of PHTX 642 Graduate Pharmacology II, Spring 2017 (General Principles of Cancer Chemotherapy), Department of Pharmacology and Toxicology, University of Louisville

Student Instructor of PHTX 642 Graduate Pharmacology II, Spring 2017 (Anti-TNF Drugs: Infliximab), Department of Pharmacology and Toxicology, University of Louisville

Student Instructor of PHTX 643 Graduate Toxicology I, Fall 2016 (Toxic Effects of Metals), Department of Pharmacology and Toxicology, University of Louisville

Student Instructor of PHTX 642 Graduate Pharmacology II, Spring 2017 (Ustekinumab Treatment in Severe Atopic Dermatitis), Department of Pharmacology and Toxicology, University of Louisville

Student Instructor of PHTX 642 Graduate Pharmacology II, Spring 2017 (Thyroid and Anti-Thyroid Drugs), Department of Pharmacology and Toxicology, University of Louisville 

2017 (Renin and Angiotensin), Department of Pharmacology and Toxicology, University of Louisville (Case Study: Flint, MI Water Crisis), Department of Pharmacology and Toxicology, University of Louisville

$\underline{\text { Lectures in invited seminars }}$

1. Royal J, Baldauf K, Yaddanapudi K, Dryden GW, Matoba N. “CTBp, a PlantMade Oral Immunotherapeutic against Ulcerative Colitis" James Graham Brown Cancer Center Colloquia on Cancer Biology and Therapeutics, Louisville, KY, 2015

2. Royal J, Youngjun Oh, Matoba N. "Epithelial Cell ER Targeted Protein = Epicertin" James Graham Brown Cancer Center Colloquia on Cancer Biology and Therapeutics, Louisville, KY, 2017

3. Royal J, Matoba N. "Plant-Made Anti-TNFa Monoclonal Antibody as an Oral Biopharmaceutical Agent against Intestinal Inflammation and Colon Cancer" Owensboro Cancer Research Program. April 2014, Owensboro, KY

4. Royal J, Matoba N. "Plant-Made Therapeutics against Intestinal Inflammation and Colon Cancer" Owensboro Cancer Research Program. October 2014, Owensboro, KY

5. Royal J, Baldauf K, Matoba N. "A Plant-Made Cholera Toxin B Subunit Variant Enhances Colonic Mucosal Wound Healing" University of Louisville Department of Pharmacology and Toxicology William J. Waddell Seminar Series 2017, March 2017, Louisville, KY

Training of graduate students

1/2017 - present Mr. Matthew Dent, University of Louisville

1/2018 - present Mrs. Melissa Henckel, University of Louisville

Mentoring/Training of undergraduate and high-school students

6/2014 - 9/2014 Ms. Bailey Nelson, University of Louisville 
6/2016 - 9/2016 Ms. Nivedha Loganathan, Dupont Manual High School

6/2017 - 12/2017 Ms. Nivedha Loganathan, Dupont Manual High School

5/2017 - present Mr. David Morris, University of Louisville

\section{PATENTS}

\section{$\underline{\text { Applications }}$}

1. Application Date: March 14, 2012

Application Number: PCT/US12/29072

Title: A plant-produced cholera toxin B subunit (CTBp) enhances mucosal wound healing and prevents colitis associated colon cancer.

\section{GRANTS AND CONTRACTS}

N/A

\section{ABSTRACTS AND PRESENTATIONS}

Oral Presentations: National/International Meetings

1. Royal J, Baldauf K, Kouokam J, Matoba N. "Plant-made cholera toxin B subunit as a candidate oral immunotherapeutic agent against ulcerative colitis" PlantBased Vaccines, Antibodies \& Biologics. June 8 - 10, 2015, Lausanne, Switzerland.

2. Royal J, Oh Y, Galandiuk S, Matoba N. "Epicertin, A Cholera Toxin B Subunit variant, Enhances Intestinal Would Healing in a Mouse Acute Colitis Model and Human Ulcerative Colitis Colon Explants via an Unfolded Protein Response" Digestive Disease Week 2018, June 2 - 5, 2018, Washington, DC.

Oral Presentations: Local/Regional Meetings

3. Royal J, Baldauf K, Matoba N. "Plant-Made Cholera Toxin B Subunit: A Candidate Oral Immunotherapeutic Agent Enhances Colonic Mucosal Wound 
Healing" Center for Predictive Medicine Retreat, November 2016, Henryville, $\mathrm{IN}$.

Poster Presentations: National/International Meetings

1. Royal J, Baldauf K, Yaddanapudi K, Dryden GW, Matoba N. “Oral Administration of a Cholera Vaccine Antigen Facilitates Colonic Mucosal Healing in a Murine Model of Colitis" Digestive Disease Week 2017, Chicago, IL, May 6 - 9, 2017.

2. Royal J, Youngjun Oh, , Galandiuk S, Matoba N. "Epicertin Enhances Intestinal Wound Healing In A Mouse Colitis Model And Human Ulcerative Colitis Colon Explants" Crohn's and Colitis Congress, 2018, Las Vegas, NV

Poster Presentations: Local/Regional Meetings

1. Royal J, Nelson B, Balduaf K, Kouokam C, Matoba N. "Plant-Made Cholera Toxin B Subunit, an Orally Active Anti-inflammatory Protein, in an Acute Colitis Mouse Model: Investigation of Effective Dose and Time of Administration" Research Louisville 2014, Louisville, KY

2. Royal J, Husk A, Hamorsky K, Bennet L, Matoba N. "Plant-Made Anti-TNFa Monoclonal Antibody; an Infliximab Biosimilar against Intestinal Inflammation and Colon Cancer" James Graham brown Cancer center 14th Annual Retreat, 2014, Louisville, KY

3. Royal J, Baldauf K, Matoba N. "Plant-Made Cholera Toxin B Subunit: A Candidate Oral Immunotherapeutic Agent Enhances Colonic Mucosal Wound Healing” Research Louisville 2015, Louisville, KY

4. Baldauf K, Royal J*, Kouokam J, Dryden G, Matoba N. "Cholera toxin B subunit protects against colitis-associated colon cancer in a mouse model" Research Louisville 2015. October 28, 2015, Louisville, KY.

5. Royal J, Baldauf K, Matoba N. "Plant-Made Cholera Toxin B Subunit: A Candidate Oral Immunotherapeutic Agent Enhances Colonic Mucosal Wound Healing" Research Louisville 2016, Louisville, KY

6. Royal J, Oh Y, Matoba N. "Epicertin, A Cholera Toxin B Subunit Variant, Enhances Intestinal Wound Healing in a mouse acute colitis model and human ulcerative colitis colon explants" Research Louisville, 2017, Louisville, KY 


\title{
PUBLICATIONS
}

\author{
Peer-Reviewed Publications (*First Author)
}

1. Baldauf KJ*, Royal JM, Hamorsky KT, Matoba N. (2015) Cholera toxin B: One subunit with many pharmaceutical applications. Toxins 7: 974-996. (PMID: 25802972)

2. Baldauf KJ* and Royal JM*, Kouokam JC, Haribabu B, Jala VR, Yaddanapudi K, Hamorsky KT, Dryden GW, Matoba N. (2017) Oral administration of a recombinant cholera toxin B subunit promotes mucosal healing in the colon. Mucosal Immunol 10: 887-900. (PMID: 27805617)

3. Royal JM*, Matoba N. (2017) Therapeutic potential of Cholera Toxin B Subunit for the treatment of inflammatory diseases of the mucosa. Toxins. 9(12). pii: E379. PMID: $\underline{29168738}$

Non-peer reviewed articles, Book chapters, Proceedings, Pamphlet or Bulletin

1. Royal, JM*, Baldauf, K., Yaddanapudi, K., Dryden, GW, \& Matoba, N. “Oral Administration of a Cholera Vaccine Antigen Facilitates Colonic Mucosal Healing in a Murine Model of Colitis" Gastroenterology, 152(5), S572-S573. doi:10.1016/S0016-5085(17)32072-3

2. Royal JM*, Oh Y, Galandiuk S, Matoba N, “Epicertin Enhances Intestinal

Wound Healing in a Mouse Colitis Model and Human Ulcerative Colitis Colon

Explants" Gastroenterology, 154(1), S16-S17. DOI: 10.1093/ibd/izy019.036 